\title{
Computational guided identification of potential leads from Acacia pennata (L.) Willd. as inhibitors for cellular entry and viral replication of SARS-CoV-2
}

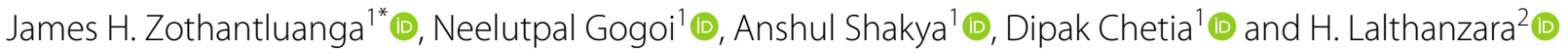

\begin{abstract}
Background: Coronavirus disease 2019 (COVID-19) caused by severe acute respiratory syndrome coronavirus 2 (SARS-CoV-2) started in 2019 and is still an on-going pandemic. SARS-CoV-2 uses a human protease called furin to aid in cellular entry and its main protease $\left(\mathrm{M}^{\text {pro }}\right)$ to achieve viral replication. By targeting these proteins, scientists are trying to identify phytoconstituents of medicinal plants as potential therapeutics for COVID-19. Therefore, our study was aimed to identify promising leads as potential inhibitors of SARS-CoV-2 $\mathrm{M}^{\text {pro }}$ and furin using the phytocompounds reported to be isolated from Acacia pennata (L.) Willd.
\end{abstract}

Results: A total of 29 phytocompounds were reported to be isolated from A. pennata. Molecular docking simulation studies revealed 9 phytocompounds as having the top 5 binding affinities towards SARS-CoV-2 Mpro and furin. Among these phytocompounds, quercetin-3-O- $a$-L-rhamnopyranoside (C_18), kaempferol 3-O- $a$-Lrhamnopyranosyl-( $1 \rightarrow 4$ )- $\beta$-D-glucopyranoside (C_4), and isovitexin (C_5) have the highest drug score. However, C_18 and C_4 were not selected for further studies due to bioavailability issues and low synthetic accessibility. Based on binding affinity, molecular properties, drug-likeness, toxicity parameters, ligand interactions, bioavailability, synthetic accessibility, structure-activity relationship, and comparative analysis of our experimental findings with other studies, C_5 was identified as the most promising phytocompound. C_5 interacted with the active site residues of

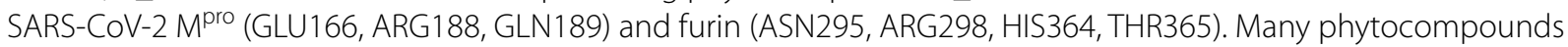
that interacted with these amino acid residues were reported by other studies as potential inhibitors of SARS-CoV-2 $\mathrm{M}^{\mathrm{pro}}$ and furin. The oxygen atom at position 18, the -OH group at position 19, and the 6 -C-glucoside were identified as the pharmacophores in isovitexin (also known as apigenin-6-C-glucoside). Other in-silico studies reported apigenin as a potential inhibitor of SARS-CoV-2 $\mathrm{M}^{\text {pro }}$ and apigenin-o-7-glucuronide was reported to show stable conformation during MD simulations with SARS-CoV-2 M ${ }^{\text {pro }}$.

Conclusion: The present study found isovitexin as the most promising phytocompound to potentially inhibit the cellular entry and viral replication of SARS-CoV-2. We also conclude that compounds having oxygen atom at position 18 (C-ring), $-\mathrm{OH}$ group at position 19 (A-ring), and 6-C-glucoside attached to the A-ring at position 3 on a $\mathrm{C}_{6}-\mathrm{C}_{3}-\mathrm{C}_{6}$ flavonoid scaffold could offer the best alternative to develop new leads against SARS-CoV-2.

Keywords: SARS-CoV-2, COVID-19, Main protease, Furin, Molecular docking, Isovitexin, Apigenin-6-C-glucoside

\footnotetext{
*Correspondence: jameshztta@gmail.com

${ }^{1}$ Department of Pharmaceutical Sciences, Faculty of Science

and Engineering, Dibrugarh University, Dibrugarh, Assam 786004, India

Full list of author information is available at the end of the article
}

(c) The Author(s) 2021. Open Access This article is licensed under a Creative Commons Attribution 4.0 International License, which permits use, sharing, adaptation, distribution and reproduction in any medium or format, as long as you give appropriate credit to the original author(s) and the source, provide a link to the Creative Commons licence, and indicate if changes were made. The images or other third party material in this article are included in the article's Creative Commons licence, unless indicated otherwise in a credit line to the material. If material is not included in the article's Creative Commons licence and your intended use is not permitted by statutory regulation or exceeds the permitted use, you will need to obtain permission directly from the copyright holder. To view a copy of this licence, visit http://creativecommons.org/licenses/by/4.0/. 


\section{Background}

The coronavirus disease 2019 (COVID-19) pandemic caused by the severe acute respiratory syndrome coronavirus 2 (SARS-CoV-2) started in December 2019 from Wuhan, Hubei Province of China [1]. To date, COVID19 is still an on-going pandemic and as of 2nd February, 2021, it has affected more than 102 million people globally and has killed more than 2 million people [2]. The clinical manifestation of COVID-19 includes shortness of breath or difficulty in breathing, fever, cough, headache, body ache, fatigue, sore throat, loss of taste or smell, nausea, vomiting, congestion or runny nose, and diarrhea [3]. Since the initial outbreak, scientists and researchers are working to develop therapies against SARS-CoV-2 [1]. Although a specific drug for COVID-19 is still not available, studies to repurpose existing drugs for COVID19 is underway [4].

With time, the pharmacological treatment options for COVID-19 had increased significantly [5]. However, problems like adverse effects, toxicity, or drug interactions seem to hinder the clinical utility of repurposed drugs for COVID-19 [4]. In the latest development, few vaccines have been authorized or approved for use against SARS-CoV-2 infection in humans [6]. Despite the breakthrough in vaccines, several deaths were reported among the recipients of those that receive the COVID19 vaccinations [7]. Amidst the dilemma surrounding the available therapeutic options for COVID-19, phytotherapy may offer a safe and effective treatment against SARS-CoV-2 infection [8, 9]. Studies reveal that viral diseases were successfully treated with the bioactive compounds from medicinal plants $[1,10,11]$. Therefore, phytomedicines may be a promising prospect for COVID-19 therapy [1].

To develop an effective antiviral therapy, it is logical to validate the possible drug targets by identifying the primary proteins involved in a viral replication process. Proteolytic activation occurs when a human protease 'furin' cleaves the spike protein (SP) of SARS-CoV-2 $[12,13]$. After the SP of SARS-CoV-2 is cleaved by furin, SARS-CoV-2 uses the S1 subunit of the spike protein (SP) to bind to the angiotensin-converting enzyme 2 and then the S2 subunit of the SP to fuse with the host cell to release its viral RNA [14]. After the viral RNA is released into the host cell, SARS-CoV-2 uses the host cell machinery to translate polyproteins from the RNA genome. Finally, cleavage of the polyproteins by the main protease $\left(\mathrm{M}^{\mathrm{pro}}\right)$ of SARS-CoV-2 results in replication and transcription of the viral genome [14-16]. The $M^{\text {pro }}$ of SARS-CoV-2 is crucial for the replication of the virus [15]. Therefore, the $\mathrm{M}^{\text {pro }}$ of SARS-CoV-2 (Fig. 1) is recognized as the most favorable drug target SARS-CoV-2 [15, $17,18]$. Cleavage of SARS-CoV-2 SP by furin is necessary for proteolytic activation, viral fusion, and viral entry into

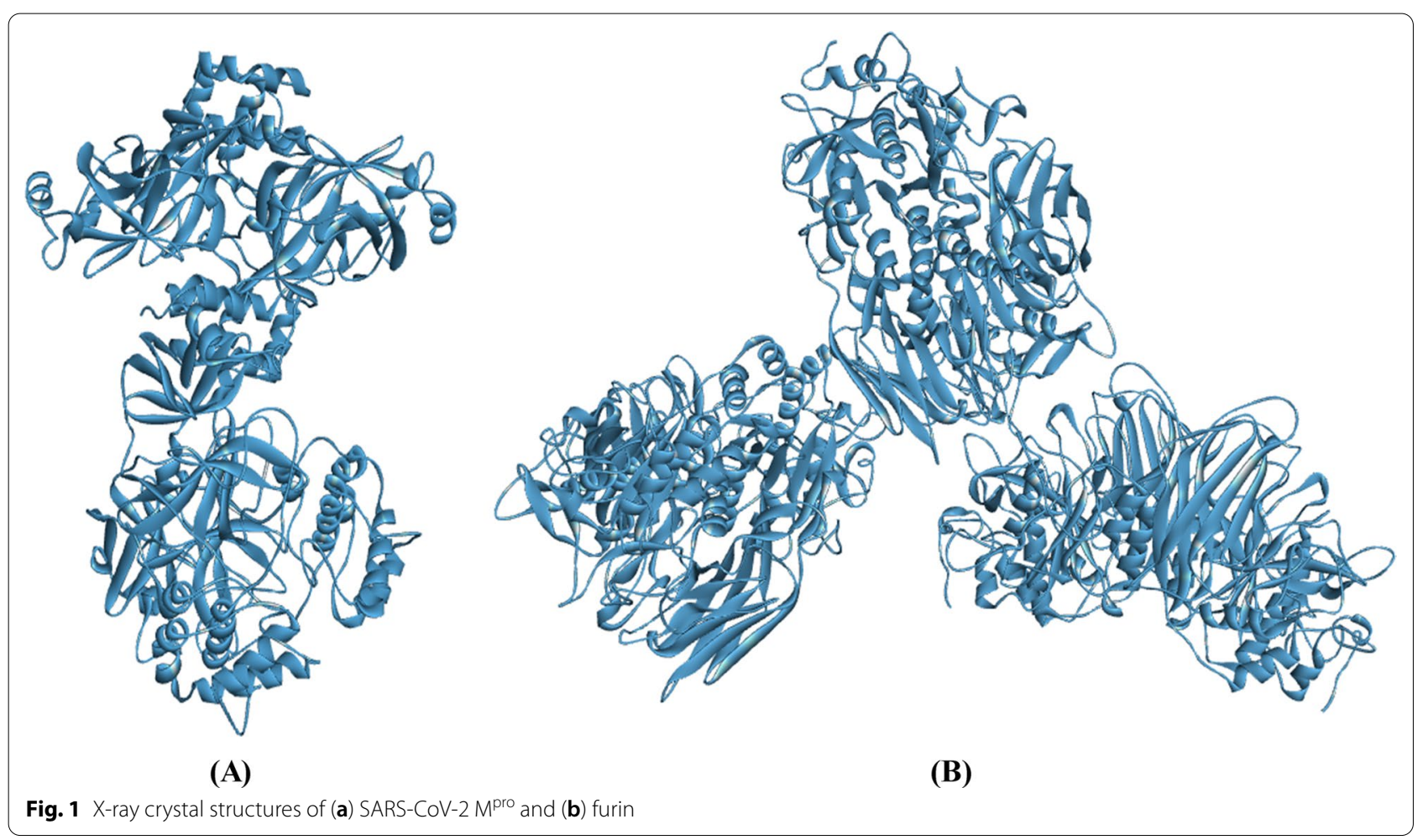


the host cell $[12,13]$. As inhibition of furin would prevent the entry of SARS-CoV-2 into the host cell, furin (Fig. 1) is also emerging as a favorable drug target in SARSCoV-2 [12].

In the quest to find a safe and effective antiviral therapy for COVID-19, bioactive compounds of medicinal plants have gained the attention of researchers and scientists $[8$, $9,19]$. The endeavor to find possible leads from medicinal plants against SARS-CoV-2 has already started [1, 20, 21]. Interestingly, several phytochemicals of medicinal plants were reported to elicit an anti-viral activity $[10,11]$. The potential of flavonoids as an antiviral agent against SARS-CoV-2 including other respiratory diseases has been reported [22, 23]. Moreover, the anti-inflammatory and antioxidant properties of flavonoids may also be beneficial to alleviate the severity of SARS-CoV-2 infection [24]. Therefore, in the search for an alternative antiSARS-CoV-2 therapy, exploring a medicinal plant that is rich in flavonoids might be helpful.

Acacia pennata (L.) Willd. (Family: Mimosaceae) is an important Southeast Asian medicinal plant that is rich in flavonoids [25-27]. A. pennata is distributed in China, Thailand, India, Sri Lanka, Myanmar, Bhutan, and Bangladesh [25]. The plant parts of Acacia species like the leaves, barks, roots, pods, twigs, gum, and flowers are traditionally used to treat various health ailments [28]. The bark and the root bark of A. pennata are traditionally used to treat respiratory ailments like bronchitis and asthma [25, 28]. Headaches and fevers are also treated with $A$. pennata [25]. The stem bark of $A$. pennata is used as a traditional anti-inflammatory agent [29]. The bark of A. pennata is also traditionally used to treat gastrointestinal ailments like cholera and dysentery $[25,29]$. Pharmacological activities like antiviral [30, 31], anti-inflammatory, antinociceptive [32], antioxidant [25], anti-parasitic [33], antimicrobial [34], and antidiabetic [35] had been scientifically investigated for $A$. pennata. The traditional utility of $A$. pennata to treat various health ailments may be attributed to the presence of flavonoids [26], terpenoids [27], phenols [28], and saponins [30] in the plant. Also, the young shoot tips of A. pennata is consumed as a vegetable as it is rich in nutrients and minerals [36-38].

A. pennata is widely available and is traditionally used to treat respiratory ailments. It is also used to treat other health ailments that are associated with COVID-19 such as fever, headache, inflammation, diarrhea like gastrointestinal issues such as dysentery, and cholera. The plant is also reported to possess anti-infective properties such as antiparasitic and antiviral activities. The facts provided above justifies the rationale to explore the phytocompounds of $A$. pennata for potential antiviral agents against SARS-CoV-2. Under urgent circumstances, computational approaches provide a great opportunity to identify natural compounds as potential inhibitors for cellular entry and viral replication of SARS-CoV-2. Therefore, the present study aims to identify potential leads against SARS-CoV-2 $\mathrm{M}^{\text {pro }}$ and furin using computational studies on the phytocompounds isolated from $A$. pennata.

\section{Methods}

The research methodology of the current study is summarized in Fig. 2.

\section{Identification of phytocompounds reported to be isolated from A. pennata}

An exhaustive online literature survey was conducted between November 2020 up to February 2021 to identify the phytocompounds that had been isolated from $A$. pennata. Academic databases like 'PubMed,' 'Science Direct', and 'Google Scholar' were utilized for the literature survey. To search relevant papers, keywords such as 'phytochemistry', 'phytoconstituents', and 'phytocompounds' were used in combination with 'Acacia pennata'. The phytocompounds that had been isolated from $A$. pennata were identified from the retrieved literature.

\section{Preparation of ligands}

The ligands used in the study were prepared manually. The chemical structures of the isolated phytocompounds

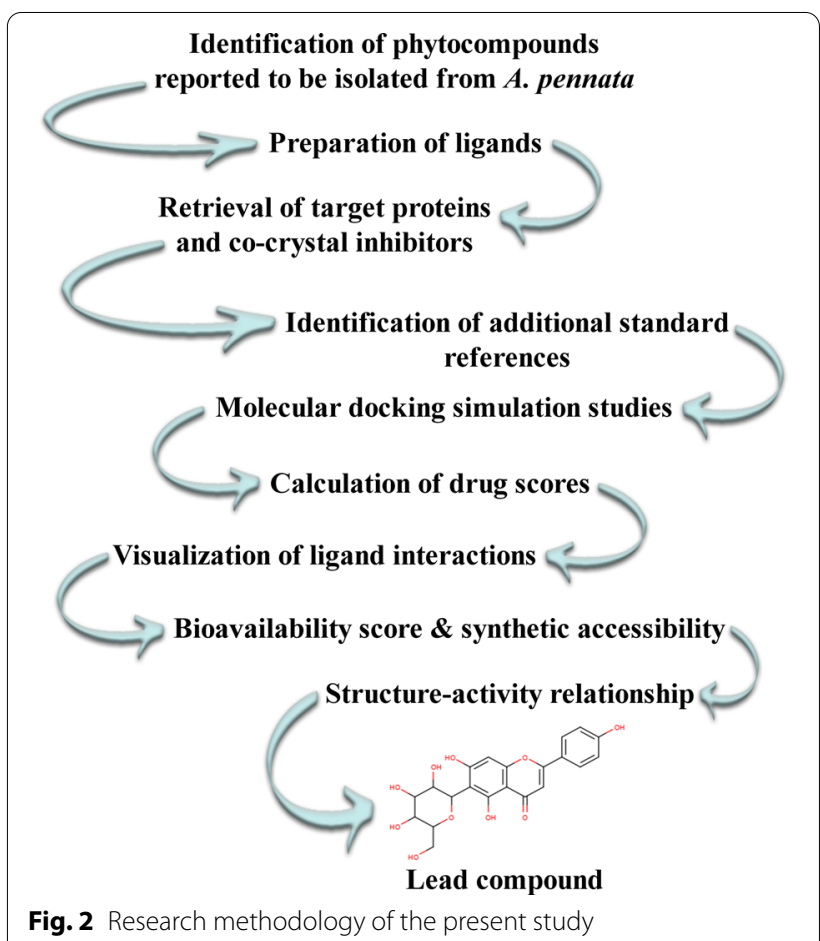


of $A$. pennata were sketched with MarvinSketch 20.10 software [39]. The correctness of the chemical structures was validated with the 'Structure checker' add-on that is available on the MarvinSketch 20.10 software. Then, the chemical structures were saved in MDL SDfile " ${ }^{*}$.sdf ".sd' format.

\section{Retrieval of target proteins and co-crystal inhibitors}

The X-ray crystal structure of SARS-CoV-2 $\mathrm{M}^{\text {pro }}$ (PDB ID: 6M2N) was downloaded in 'pdb' format from the RCSB-PDB website [40]. The co-crystal inhibitor (3WL) of SARS-CoV-2 $\mathrm{M}^{\text {pro }}$ was downloaded in 'sdf' format from the RCSB-PDB website [41]. The X-ray crystal structure of human furin (PDB ID: 4RYD) was downloaded in '.pdb' format from the RCSB-PDB website [42]. The co-crystal inhibitor (para-guanidinomethyl-PhacR-Tle-R-Amba) of human furin was also downloaded in 'sdf' format from the RCSB-PDB website [43]. The protein structures were pre-processed to remove water. The co-crystal inhibitors obtained along with the target proteins will be used as standard references.

\section{Identification of additional standard references}

An anticancer drug 'carmofur' was reported to inhibit SARS-CoV-2 $\mathrm{M}^{\text {pro }}$ in Vero E6 cells $\left(\mathrm{EC}_{50}=24.30 \pm 3.61 \mu \mathrm{M}\right)$ [44]. Another study reported that naphthofluorescein inhibited furin that is responsible for the cleavage of SARS-CoV-2 SP [12]. Owing to their experimental evidence against SARS-CoV-2 $\mathrm{M}^{\text {pro }}$ and furin, carmofur and naphthofluorescein will be used as a standard reference in addition to the co-crystal inhibitors. The chemical structures of carmofur and naphthofluorescein were prepared with MarvinSketch 20.10 software [39]. The correctness of their structures was checked using the 'Structure checker' add-on available on the MarvinSketch 20.10 software. Their structures were then saved in MDL SDfile ".sdf" .sd' format.

\section{Molecular docking simulation studies}

To predict the binding affinity between the target proteins and the phytocompounds, molecular docking simulation studies were carried out with Autodock Vina 1.1.2 on PyRx 0.8 virtual screening platform $[45,46]$. In this study, chain A of SARS-CoV-2 $\mathrm{M}^{\text {pro }}$ and chain A of furin were used as the drug targets [40, 42]. According to the standard protocols, the three-dimensional affinity grid box in the Vina search space of PyRx 0.8 tool should enclose the entire protein for blind docking [47, 48]. However, the protein-co-crystal inhibitor complex was used to manually identify the three-dimensional coordinates of the active binding sites for SARS-CoV-2 $\mathrm{M}^{\text {pro }}$ and furin on the PyRx 0.8 tool. After the target protein was loaded onto the PyRx virtual screening platform, the target protein was expanded to reveal different chains that made up the protein. All the chains except chain A were removed from the scene for each protein. The protein-data bank format of the chain A of each protein was converted to 'pdbqt'. format wherein hydrogens were added during the conversion process. The sequence of the amino acids including the co-crystal inhibitor were revealed by expanding chain A. The atoms of the cocrystal inhibitor were labelled to identify the accurate location of the co-crystal inhibitor that is present at the active binding site of the protein. The centre of the 3D affinity grid box ( $x=25.0 \AA$; $y=25.0 \AA ; z=25.0 \AA)$ and the co-crystal inhibitor were adjusted to align so that the affinity grid box was able to cover all the amino acid residues at the active binding site of the protein. Then, the active binding site coordinates of SARS-CoV- $2 \mathrm{M}^{\text {pro }}$ $(x=-33.1066 ; y=-64.6263 ; z=41.2995)$ and furin $(x=28.0166 ; y=28.3695 ; z=-6.0437)$ were manually adjusted for each docking process to simulate the active binding sites of the co-crystal ligands. The rest of the parameters such as energy minimization for protein and ligands were kept default. The molecular docking simulation studies were carried out as per the standard protocols of PyRx software for the phytocompounds and the standard references [47]. The phytocompounds with the top 5 binding affinities towards the active binding site of SARS-CoV-2 $\mathrm{M}^{\text {pro }}$ and furin were selected for further analysis.

\section{Calculation of drug scores}

The drug score of the standard references and the phytocompounds with the top 5 binding affinities for SARS$\mathrm{CoV}-2 \mathrm{M}^{\text {pro }}$ and furin were calculated using ORISIS Data Warrior v5.2.1 software [49]. The Data Warrior v.5.2.1 software takes several parameters (molecular properties, drug-likeness, and toxicity) into consideration to calculate the drug score. To select a phytocompound for further studies, it is important to make sure that the compound is safe and has good molecular properties. The Data Warrior v.5.2.1 software provides a low drug score for toxic compounds with undesirable molecular properties. Therefore, three phytocompounds with the highest drug scores were selected for further analysis.

\section{Visualization of ligand interactions}

Even though a phytocompound is found to have a high binding affinity towards a target protein, it is important to make sure that the phytocompound interacts with the amino acid residues at the active binding site of the protein. Protein-ligand interactions like hydrogen bonding, hydrophobic interactions, electrostatic interactions, and the interacting active site residues of the proteins were visualized for both the standard references and the three 
phytocompounds with the highest drug scores. Discovery Studio Visualizer v20.1.0.19295 software was used to visualize the 2-dimensional ligand interactions. The 3-dimensional binding pose of the phytocompounds and the standard references towards the target proteins were visualized using PyMOL molecular graphics system, Version 2.4.1 Schrodinger, LLC. [50]. The ligand interactions of the standard references and the potential leads were comparatively analyzed.

\section{Bioavailability score and synthetic accessibility}

A compound can be effective as a drug only if it is bioavailable [51]. Since bioavailability issues can slow down the process of drug development [52], preliminary investigation on the bioavailability of the phytocompounds is important. Synthetic accessibility is a fingerprint-based computational approach to determine the level of difficulty for synthesizing a compound [51]. As we aim to identify a potential lead from phytocompounds, it will be favourable for the identified lead to have high synthetic accessibility so that potent antiviral agents can be synthesized using the scaffold and pharmacophores of the lead compound. Therefore, after it was confirmed that multiple interactions occurred between the phytocompounds and the target protein, the bioavailability score and the synthetic accessibility of the phytocompounds were predicted with the SwissADME web tool [51].

\section{Structure-activity relationship}

The structure-activity relationship of the phytocompound with the highest bioavailability score and the best synthetic accessibility was analyzed. A mapped structure of the phytocompound was prepared with MarvinSketch 20.10 software. The functional groups, chains, or atoms of the structure of the phytocompound that interacted with the amino acid residues at the active binding site were manually identified. The observations made in the study were compared with several other published data.

\section{Results}

\section{Phytocompounds reported to be isolated from A. pennata}

The list of phytocompounds that had been reported to be isolated from A. pennata is given in Table 1 . The chemical structures of all the isolated phytocompounds are also presented in Fig. 3.

\section{Molecular docking simulation studies}

The binding affinities of the phytocompounds and the standard references (co-crystal inhibitors and additional standard references) towards SARS-CoV-2 $\mathrm{M}^{\text {pro }}$ and furin are given in Table 2.

\section{Drug score}

The molecular properties (molecular weight and lipophilicity), drug-likeness, toxicity (mutagenicity, tumorigenic, reproductive effective, and irritant), and the overall drug score of the standard references and the phytocompounds with the top 5 binding affinities towards SARS-CoV- $2 \mathrm{M}^{\text {pro }}$ and furin are given in Tables 3 and 4 respectively.

\section{Ligand interactions}

Ligand interactions of the three phytocompounds with the highest drug scores (C_18, C_4 , and C_5) and the standard references (3WL and carmofur) with the amino acid residues at the active binding site of SARS$\mathrm{CoV}-2 \mathrm{M}^{\mathrm{pro}}$ in 2-dimensional view is given in Fig. 4. The 3 -dimensional binding pose of the phytocompounds and the standard references at the active binding pockets of SARS-CoV-2 $\mathrm{M}^{\text {pro }}$ is given in Fig. 5. The binding parameters of the standard references and the phytocompounds with the amino acid residues at the active binding site of SARS-CoV-2 $\mathrm{M}^{\text {pro }}$ are given in Table 5.

Ligand interactions of the three phytocompounds with the highest drug scores (C_18, C_4 , and C_5) and the standard references (PGPRTRA and naphthofluorescein) with the amino acid residues at the active binding site of furin in 2-dimensional view is given in Fig. 6. The 3 -dimensional binding pose of the phytocompounds and the standard references at the active binding pockets of furin is given in Fig. 7. The binding parameters of the standard references and the phytocompounds with the active binding site amino acid residues of furin are given in Table 6.

\section{Bioavailability score and synthetic accessibility}

The bioavailability score and synthetic accessibility of the three phytocompounds with the highest drug scores are given in Table 7. A compound should have a high bioavailability score with a low numerical value for its synthetic accessibility $(1=$ easy to synthesize; $10=$ difficult to synthesize) [51].

\section{Structure-activity relationship of $\mathrm{C}_{-} 5$}

The mapped structure of the phytocompound (C_5) with the highest bioactivity score and the best synthetic accessibility is given in Fig. 8.

The hydroxyl $(-\mathrm{OH})$ group at position 19 attached to the A-ring of the $\mathrm{C}_{6}-\mathrm{C}_{3}-\mathrm{C}_{6}$ scaffold interacts with SARS-COV-2 $\mathrm{M}^{\text {pro }}$ by forming two conventional hydrogen bonds with GLU166 at the active binding site of the protein (Figs. 4 and 8 ). The $-\mathrm{OH}$ group at positions 28 and 31 of the 6-C glucoside attached to the A-ring of the $\mathrm{C}_{6}-\mathrm{C}_{3}-\mathrm{C}_{6}$ scaffold interacts with SARS-CoV-2 $\mathrm{M}^{\text {pro }}$ 
Table 1 List of phytocompounds isolated from A. pennata

\begin{tabular}{|c|c|c|c|c|c|}
\hline SI.No & Phytocompounds & Compound ID & Chemical class & Isolated from & References \\
\hline 1 & Quercetin 4'-O-a-L-rhamnopyranosyl-3-O- $\beta$-D-allopyranoside & C_1 & Flavonoid & Leaves & [32] \\
\hline 2 & Apigenin 6-C-[2"-O-(E)-feruloyl- $\beta$-D-glucopyranosyl]-8-C- $\beta$-glucopyranoside & C_2 & Flavonoid & Leaves & [32] \\
\hline 3 & Isorhamnetin 3-O-a-L-rhamnopyranoside & C_3 & Flavonoid & Leaves & [32] \\
\hline 4 & Kaempferol 3-O-a-L-rhamnopyranosyl-( $1 \rightarrow 4)$ - $\beta$-D-glucopyranoside & C_4 & Flavonoid & Leaves & [32] \\
\hline 5 & Isovitexin & C_5 & Flavonoid & Leaves & [32] \\
\hline 6 & Taepeenin D & C_6 & Terpenoid & Leaves & [27] \\
\hline 7 & (+)-drim-8-ene & C_7 & Terpenoid & Leaves & [27] \\
\hline 8 & 8,15-labdanediol & C_8 & Terpenoid & Leaves & [27] \\
\hline 9 & Labdanolic acid & C_9 & Terpenoid & Leaves & [27] \\
\hline 10 & Quercetin 3-O- $\beta$-D-glucopyranosyl-4-O- $\beta$ - D-glucopyranoside & C_10 & Flavonoid & Leaves & {$[27]$} \\
\hline 11 & Tetracosane & C_11 & Alkane & Twigs & [53] \\
\hline 12 & 1-(heptyloxy)-octadecane & C_12 & Alkane & Twigs & [53] \\
\hline 13 & Methyl tridecanoate & C_13 & Ester & Twigs & [53] \\
\hline 14 & Arborinone & C_14 & Terpenoid & Twigs & [53] \\
\hline 15 & Confertamide A & C_15 & - & Twigs & [53] \\
\hline 16 & 4-hydroxy-1-methyl-pyrrolidin-2-carboxylic acid & C_16 & Alkaloid & Twigs & [53] \\
\hline 17 & Quercetin-3-O- $\beta$-D-glucopyranoside & C_17 & Flavonoid & Aerial parts & {$[26]$} \\
\hline 18 & Quercetin-3-O-a-L-rhamnopyranoside & C_18 & Flavonoid & Aerial parts & {$[26]$} \\
\hline 19 & Chrysin-7-O- $\beta$-D-glucopyranoside & C_19 & Flavonoid & Aerial parts & [26] \\
\hline 20 & Kaempferol 3-O-a-L-rhamnopyranoside & C_20 & Flavonoid & Aerial parts & [26] \\
\hline 21 & Pinocembrin-7-O- $\beta$-D-glucopyranoside & C_21 & Flavonoid & Aerial parts & [26] \\
\hline 22 & Koaburanin & C_22 & Flavonoid & Aerial parts & [26] \\
\hline 23 & 5,7-dihydroxyflavone 7-O- $\beta$-D-glucopyranosyl-8-C- $\beta$-boivinopyranoside & C_23 & Flavonoid & Aerial parts & [26] \\
\hline 24 & 5,7-dihydroxyflavone 6-C- $\beta$-boivinopyranosyl-7-O- $\beta$-D-glucopyranoside & C_24 & Flavonoid & Aerial parts & [26] \\
\hline 25 & $\begin{array}{l}\text { (2R)-4,7-dihydroxyflavan-(4a } \rightarrow \text { 8)-(2R,3S)-3,5,7-trihdyroxyflavan-3"-O-a-L- } \\
\text { rhamnopyranoside }\end{array}$ & C_25 & Flavonoid & Aerial parts & [26] \\
\hline 26 & $\begin{array}{l}\text { (2S)-5,7-dihydroxyflavan-7-O- } \beta \text {-D-glucopyranoside-(4a } \rightarrow \text { 8)-epiafzelechin-3-O- } \\
\text { gallate }\end{array}$ & C_26 & Flavonoid & Aerial parts & [26] \\
\hline 27 & (2R,3S)-3,5,7-trihdyroxyflavan-3-O-a-L-rhamnopyranoside & C_27 & Flavonoid & Aerial parts & [26] \\
\hline 28 & 21ß-O-[(2E)-6-hydroxyl-2,6-dimethyl-2,7-octadienoyl] pitheduloside G & C_28 & Saponin & Stem & [30] \\
\hline 29 & Pitheduloside G & C_29 & Saponin & Stem & [30] \\
\hline
\end{tabular}

by forming conventional hydrogen bonds with ARG188 and GLN189 at the active binding site of the protein respectively (Figs. 4 and 8 ).

The $-\mathrm{OH}$ group at position 19 of the A-ring and the oxygen atom at position 18 of the $\mathrm{C}$-ring interacts with furin by forming a conventional hydrogen bond with ASN295 at the active binding site of the protein (Figs. 6 and 8 ). The $-\mathrm{OH}$ group at positions 27 and 28 of the 6-C glucoside attached to the A-ring also interacts with furin by forming a conventional hydrogen bond with THR365 (Figs. 6 and 8). The $-\mathrm{OH}$ group at position 28 of the 6-C glucoside also formed a conventional hydrogen bond with HIS364 of furin. The B-ring of the $\mathrm{C}_{6}-\mathrm{C}_{3}-\mathrm{C}_{6}$ scaffold formed electrostatic interaction with ARG298 of furin (Figs. 6 and 8).

\section{Discussion}

Phytocompounds reported to be isolated from A. pennata Literature survey reveals that 29 phytocompounds belonging to different classes of secondary metabolites like flavonoids, alkaloids, terpenoids, and saponins had been isolated from the stem, aerial parts, twigs, and leaves A. pennata (Table 1, Fig. 3). Recently, a team of researchers found that the hydromethanolic extract of $A$. pennata offers protection against DNA damage induced by acetaminophen in rat liver and they had also detected 5 new flavonoid-glycosides (Apigenin 6,8-di-C-hexoside, Apigenin-6-C-pentoside-8-C-hexoside, Apigenin-6-Chexoside-8-C-pentoside, Kaempferol 3,7-di-O-hexoside, and Luteolin-6-C-pentoside-8-C-hexoside) in the hydromethanolic extract [54]. However, these 


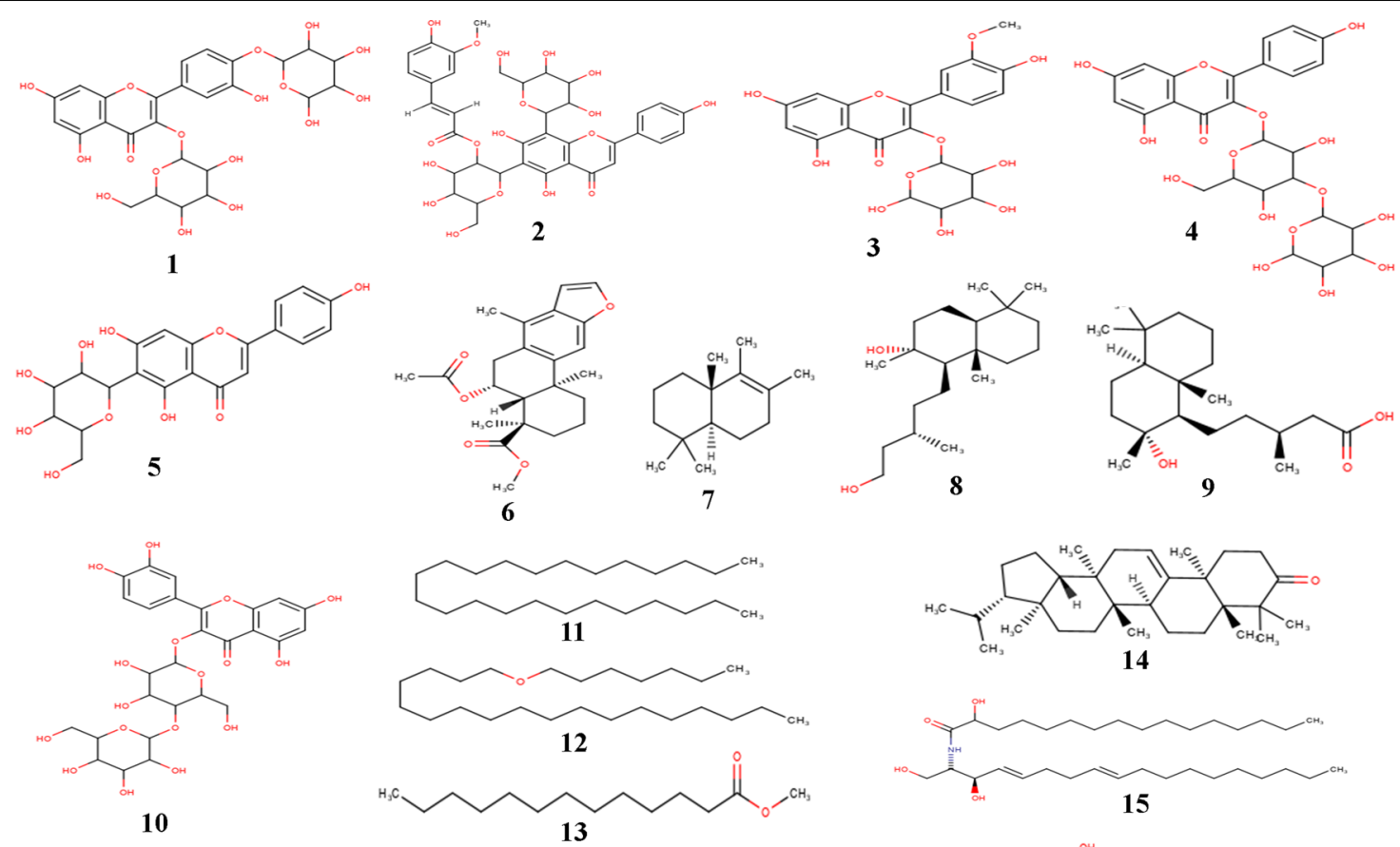

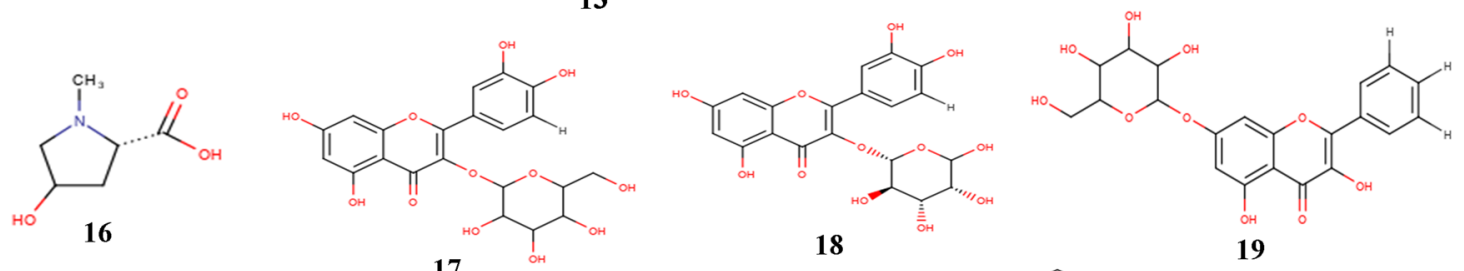<smiles>Cc1cc(-c2oc3cc(O)cc(Br)c3c(=O)c2OC2OC(CO)C(O)C(O)C2O)cc(I)c1Br</smiles>

$$
17
$$

18
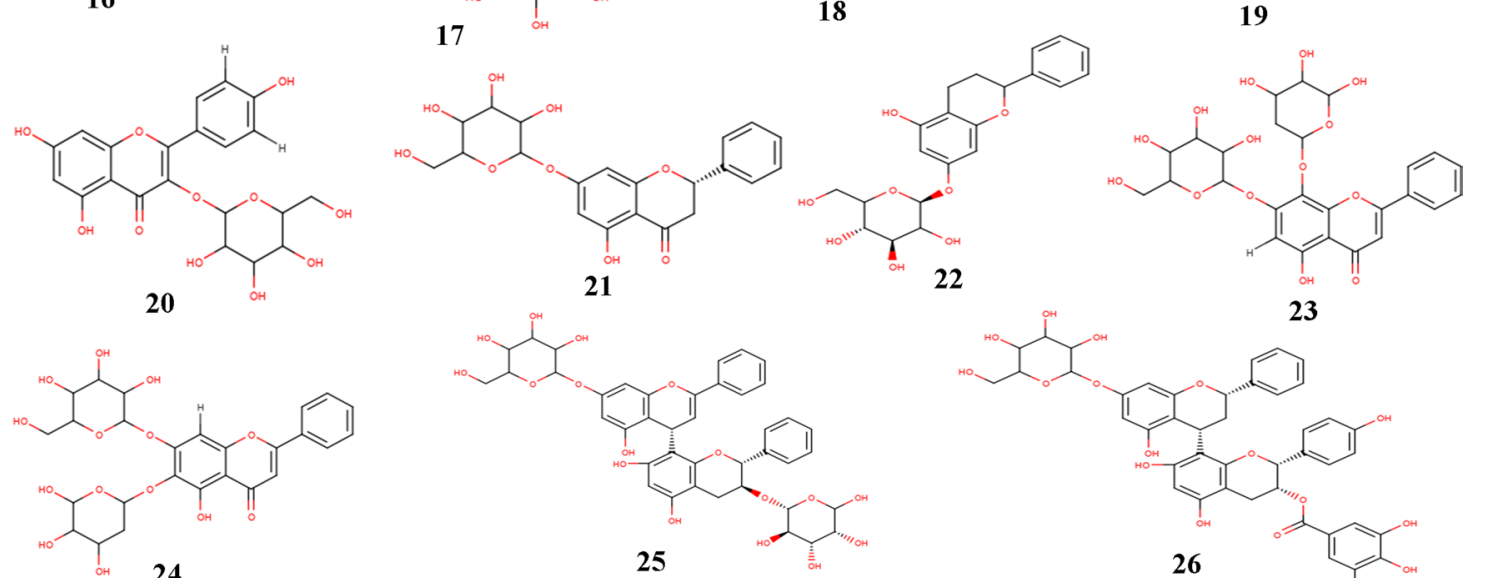

22

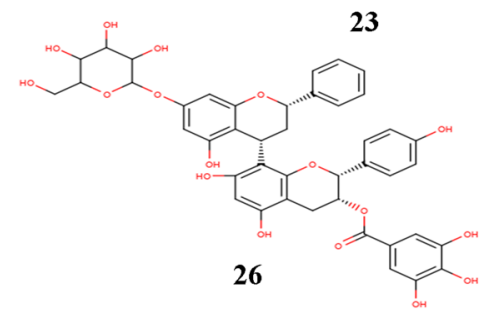<smiles>CCC1OC(OC2Cc3c(F)cc(O)cc3NC2c2ccccc2)C(O)C(O)C1C</smiles>

27

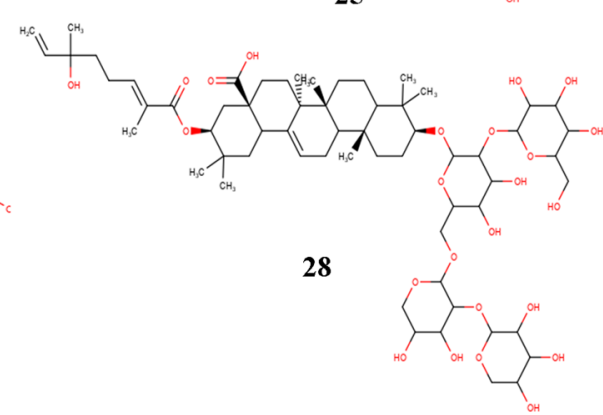

Fig. 3 Chemical structures of phytocompounds reported to be isolated from A. pennata

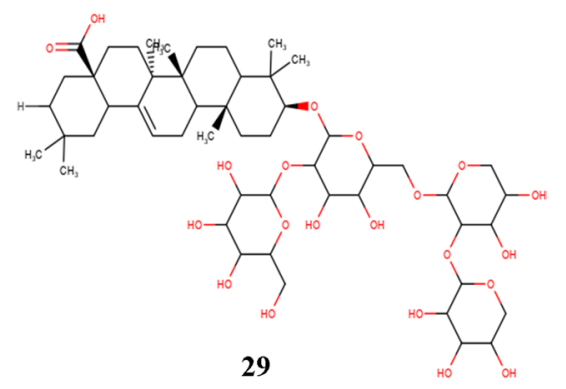


Table 2 Binding affinities $(\mathrm{kcal} / \mathrm{mol})$ of the phytocompounds towards SARS-CoV-2 $\mathrm{M}^{\text {pro }}$ and furin

\begin{tabular}{|c|c|c|c|}
\hline SI. No & Compound ID & SARS-CoV-2 $\mathrm{M}^{\text {pro }}$ & Furin \\
\hline 1 & $C_{-} 1$ & -7.3 & -8.2 \\
\hline 2 & C_2 & -6 & -6.5 \\
\hline 3 & C_3 & -6.6 & -7.6 \\
\hline 4 & $C_{4} 4$ & -7.2 & -8 \\
\hline 5 & C_5 & -7.3 & -8 \\
\hline 6 & C_6 & -6 & -6.6 \\
\hline 7 & $C_{-} 7$ & -5.4 & -5.5 \\
\hline 8 & C_8 & -5 & -5.6 \\
\hline 9 & C_9 & -6 & -6.3 \\
\hline 10 & C_10 & -6.4 & -7.1 \\
\hline 11 & C_11 & -3.6 & -4.2 \\
\hline 12 & C_12 & -3.9 & -4.3 \\
\hline 13 & C_13 & -3.9 & -3.8 \\
\hline 14 & C_14 & -6.6 & -8.1 \\
\hline 15 & C_15 & -4.9 & -5.1 \\
\hline 16 & C_16 & -4.6 & -4.8 \\
\hline 17 & C_17 & -6.5 & -7.8 \\
\hline 18 & C_18 & -7.6 & -2 \\
\hline 19 & C_19 & -7 & -7.9 \\
\hline 20 & C_20 & -6.9 & -7.5 \\
\hline 21 & C_21 & -7.2 & -7.9 \\
\hline 22 & C_22 & -6.7 & -7.6 \\
\hline 23 & C_23 & -7.3 & -8.1 \\
\hline 24 & C_24 & -7.3 & -7.9 \\
\hline 25 & C_25 & -7.7 & -7.7 \\
\hline 26 & C_26 & -8 & -8.2 \\
\hline 27 & C_27 & -1.7 & -2.3 \\
\hline 28 & C_28 & -7 & -8.3 \\
\hline 29 & C_29 & -6.7 & -9 \\
\hline 30 & $3 \mathrm{WL}$ & -6.7 & - \\
\hline 31 & Carmofur & -5.6 & - \\
\hline 32 & $\begin{array}{l}\text { Para-guanidinomethyl- } \\
\text { Phac-R-Tle-R-Amba }\end{array}$ & - & -7 \\
\hline 33 & Naphthofluorescein & - & -10 \\
\hline
\end{tabular}

newly detected phytocompounds were not included in the study as there is still no report on their isolation. Another recent study reported that phosphodiesterase- 5 was inhibited by the ethanolic extract of the leaves of A. pennata [55]. The same study highlighted four phytocompounds (quercetin-3-O- $\beta$-D-glucopyranoside, chrysin-7-O- $\beta$-D-glucopyranoside, koaburanin, and pinocembrin-7-O- $\beta$-D-glucopyranoside) as identified phytochemicals in the ethanolic extract [55]. The isolation of these four phytocompounds had been reported and are included in the present study. The majority of the isolated phytocompounds $(n=17)$ from $A$. pennata belonged to the class of flavonoids. The antiviral activity of flavonoids is well explored [56,57] and their potential role against coronavirus infection had also been thoroughly discussed $[24,58]$. Since $A$. pennata is rich in flavonoids, the chances of finding a potential lead from $A$. pennata as a SARS-CoV-2 inhibitor also increases. The study was initially proposed to limit the virtual screening to isolated flavonoids only. However, a literature survey revealed that a saponin ' $21 \beta-O-[(2 E)-6$-hydroxyl-2,6dimethyl-2,7-octadienoyl] pitheduloside G' isolated from A. pennata exhibited an antiviral activity [30]. Therefore, in addition to flavonoids, the chances to find a potential lead from other classes of secondary metabolites also exist. Thus, irrespective of their chemical class, it was decided to screen all the reported phytocompounds that had been isolated from A. pennata.

\section{Molecular docking simulation studies}

The molecular docking simulation experiment revealed the binding affinities of the phytocompounds and the standard references (co-crystal inhibitors and additional standard references) towards SARS-CoV-2 $\mathrm{M}^{\text {pro }}$ and furin (Table 2). A high binding affinity signifies that a ligand will bind to the target protein with minimum energy [1]. Thus, a ligand with a high binding affinity towards the target protein is often desirable to be selected for further studies. In general, the binding affinities of the phytocompounds towards SARS-CoV-2 $\mathrm{M}^{\text {pro }}$ ranged from -8.0 to $-1.7 \mathrm{kcal} / \mathrm{mol}$ while the binding affinities of the phytocompounds towards furin ranged from -9.0 to $-2.0 \mathrm{kcal} / \mathrm{mol}$. When a molecular docking simulation study was conducted on a PyRx 0.8 software, a total of 9 poses were generated for each ligand [47]. The PyRx 0.8 automatically selects the first pose with the highest binding affinity as the best pose.

Phytocompounds with the top 5 binding affinities towards SARS-CoV-2 $\mathrm{M}^{\text {pro }}$ are C_26 $(-8.0 \mathrm{kcal} /$ $\mathrm{mol})$, C_25 $(-7.7 \mathrm{kcal} / \mathrm{mol}), C_{-} 18(-7.6 \mathrm{kcal} / \mathrm{mol})$, C_1 $(-7.3 \mathrm{kcal} / \mathrm{mol})$, C_5 $(-7.3 \mathrm{kcal} / \mathrm{mol})$, C_23 $(-7.3 \mathrm{kcal} /$ $\mathrm{mol})$, C_24 $(-7.3 \mathrm{kcal} / \mathrm{mol})$, C_4 $(-7.2 \mathrm{kcal} / \mathrm{mol})$ and C_21 (-7.2 kcal $/ \mathrm{mol})$ (Table 2). The co-crystal inhibitor ' 3 WL' and the additional standard reference 'Carmofur' showed a binding affinity of $-6.7 \mathrm{kcal} / \mathrm{mol}$ and $-5.6 \mathrm{kcal} /$ mol respectively (Table 2). The phytocompounds with the top 5 binding affinities (C_26, C_25, C_18, C_1, C_5 , C_23, C_24, C_4 , and C_21) showed a better binding affinity towards SARS-CoV-2 $\mathrm{M}^{\text {pro }}$ than the standard references (3WL and carmofur).

Phytocompounds with the top 5 binding affinities towards furin are C_29 $(-9.0 \mathrm{kcal} / \mathrm{mol})$, C_28 $(-8.3 \mathrm{kcal} / \mathrm{mol})$, C_1 $(-8.2 \mathrm{kcal} / \mathrm{mol})$, C_26 $(-8.2 \mathrm{kcal} /$ $\mathrm{mol}), \quad$ C_14 $\quad(-8.1 \mathrm{kcal} / \mathrm{mol}), \quad$ C_23 $\quad(-8.1 \mathrm{kcal} /$ $\mathrm{mol}), \quad$ C_4 $\quad(-8.0 \mathrm{kcal} / \mathrm{mol}), \quad$ C_5 $\quad(-8.0 \quad \mathrm{kcal} / \mathrm{mol})$ and C_18 $(-8.0 \mathrm{kcal} / \mathrm{mol})$ (Table 2). The co-crystal 
Table 3 Molecular properties, drug-likeness, toxicity parameters, and the overall drug score of phytocompounds with the top 5 binding affinities and the standard references towards SARS-CoV-2 $\mathrm{M}^{\text {pro }}$

\begin{tabular}{|c|c|c|c|c|c|c|c|c|c|c|c|}
\hline SI. No & Compound ID & Mol wt & cLogP & $\mathrm{H}-\mathrm{A}$ & $H-D$ & $\mathrm{DL}$ & MG & TG & $\mathrm{RE}$ & IT & Drug score \\
\hline 1 & C_26 & 828.774 & 3.0928 & 17 & 11 & -3.9418 & None & None & High & None & 0.1106131 \\
\hline 2 & C_25 & 806.767 & 1.1416 & 17 & 11 & -3.7831 & None & None & None & None & 0.2135499 \\
\hline 3 & C_18 & 450.351 & -0.0954 & 12 & 8 & 0.32236 & None & None & None & None & 0.6301938 \\
\hline 4 & C_1 & 626.518 & -1.89 & 17 & 11 & -3.6941 & None & None & None & None & 0.2942673 \\
\hline 5 & C_5 & 432.380 & -0.078 & 10 & 7 & -1.9977 & None & None & None & None & 0.4577336 \\
\hline 6 & C_23 & 564.494 & -0.5393 & 14 & 8 & -2.2846 & High & High & None & None & 0.1216019 \\
\hline 7 & C_24 & 564.494 & -0.5393 & 14 & 8 & -2.2846 & None & None & None & None & 0.3377829 \\
\hline 8 & C_4 & 596.492 & -1.5868 & 16 & 10 & 0.38943 & None & None & None & None & 0.4808296 \\
\hline 9 & C_21 & 418.397 & 0.5121 & 9 & 5 & -3.7146 & None & None & None & None & 0.4171902 \\
\hline 10 & $3 \mathrm{WL}$ & 270.239 & 2.3357 & 5 & 3 & 0.28194 & None & None & None & None & 0.6981475 \\
\hline 11 & Carmofur & 257.264 & 1.4226 & 6 & 2 & -13.647 & High & None & High & None & 0.16024 \\
\hline
\end{tabular}

Mol wt. $=$ Molecular weight; $\mathrm{CLog} \mathrm{P}=$ partition coefficient between $\mathrm{n}-$ octanol and water; $\mathrm{H}-\mathrm{A}=\mathrm{Hydrogen}$ acceptor; $\mathrm{H}-\mathrm{D}=\mathrm{Hydrogen}$ donor; $\mathrm{DL}=\mathrm{Druglikeness;}$ MG = Mutagenicity; TG = Tumorigenic; RE = Reproductive effective; IT = Irritant

Table 4 Molecular properties, drug-likeness, toxicity parameters, and the overall drug score of phytocompounds with the top 5 binding affinities and the standard references towards furin

\begin{tabular}{|c|c|c|c|c|c|c|c|c|c|c|c|}
\hline SI. No & Compound ID & Mol wt & CLogP & H-A & H-D & $\mathrm{DL}$ & MG & TG & $\mathrm{RE}$ & IT & Drug score \\
\hline 1 & C_29 & 1045.22 & -0.0801 & 21 & 12 & -11.577 & None & None & None & None & 0.181405 \\
\hline 2 & C_28 & 1227.44 & 1.8063 & 24 & 13 & -16.06 & None & None & None & High & 0.088529 \\
\hline 3 & $C_{-} 1$ & 626.518 & -1.89 & 17 & 11 & -3.6941 & None & None & None & None & 0.2942673 \\
\hline 4 & C_26 & 828.774 & 3.0928 & 17 & 11 & -3.9418 & None & None & High & None & 0.1106131 \\
\hline 5 & C_14 & 438.737 & 7.815 & 1 & 0 & -6.3613 & None & None & None & None & 0.1257381 \\
\hline 6 & C_23 & 564.494 & -0.5393 & 14 & 8 & -2.2846 & High & High & None & None & 0.1216019 \\
\hline 7 & $C_{-} 4$ & 596.492 & -1.5868 & 16 & 10 & 0.38943 & None & None & None & None & 0.4808296 \\
\hline 8 & C_5 & 432.380 & -0.078 & 10 & 7 & -1.9977 & None & None & None & None & 0.4577336 \\
\hline 9 & C_18 & 450.351 & -0.0954 & 12 & 8 & 0.32236 & None & None & None & None & 0.6301938 \\
\hline 10 & PGPRTRA & 763.950 & -2.896 & 19 & 15 & -4.1097 & None & None & None & None & 0.255768 \\
\hline 11 & Naphthofluorescein & 432.430 & 6.1173 & 5 & 2 & -1.2682 & Low & High & None & None & 0.0831259 \\
\hline
\end{tabular}

Mol wt. = Molecular weight; $\mathrm{CLogP}=$ partition coefficient between $\mathrm{n}-$ octanol and water; $\mathrm{H}-\mathrm{A}=\mathrm{Hydrogen}$ acceptor; $\mathrm{H}-\mathrm{D}=\mathrm{Hydrogen}$ donor; $\mathrm{DL}=\mathrm{Druglikeness}$; $\mathrm{MG}=$ Mutagenicity; TG = Tumorigenic; RE = Reproductive effective; IT = Irritant

inhibitor 'Para-guanidinomethyl-Phac-R-Tle-R-Amba' (PGPRTRA) and the additional standard reference 'Naphthofluorescein' showed a binding affinity of $-7.0 \mathrm{kcal} /$ $\mathrm{mol}$ and $-10.0 \mathrm{kcal} / \mathrm{mol}$ respectively (Table 2 ). The phytocompounds (C_29, C_28, C_1, C_26, C_14, C_23, C_4, C_5 , and C_18) showed a better binding affinity towards furin than the co-crystal inhibitor (PGPRTRA) but not a better binding affinity than the additional standard reference (Naphthofluorescein).

\section{Drug score of phytocompounds with the top 5 binding affinities}

The molecular properties, drug-likeness, toxicity parameters, and the overall drug score of the standard references and the phytocompounds with the top 5 binding affinities towards SARS-CoV-2 $\mathrm{M}^{\text {pro }}$ and furin are given in Tables 3 and 4 respectively. The ORISIS Data Warrior v5.2.1 software uses molecular properties like molecular weight, cLogP, hydrogen acceptors, hydrogen donors, drug-likeness, and toxicity parameters like mutagenicity, tumorigenic, reproductive effective, and irritant to calculate the overall drug score of a compound. Toxicity is one of the reasons why many drugs had to be withdrawn from the market [59]. In addition to the binding affinity, the drug score can be used as a filter to narrow down and select suitable compounds for further studies. Thus, the drug score provides a referential value that can be used to judge the overall potential of a compound to qualify as a drug [60]. The reference standards against SARS-CoV-2 $\mathrm{M}^{\text {pro }}$ had a drug score of 0.6981475 (3WL) and 0.16024 


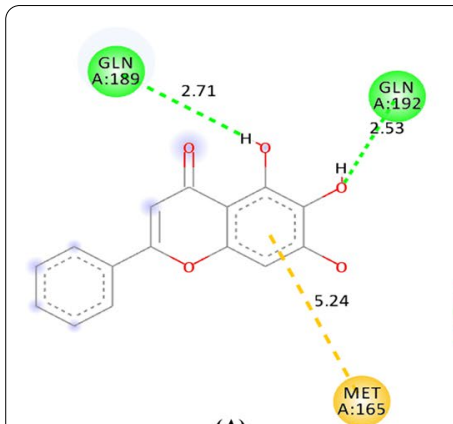

(A)

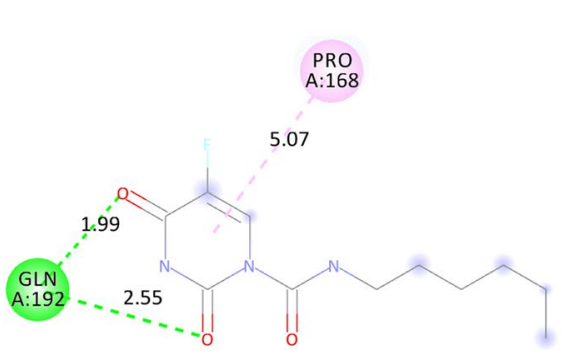

(B)

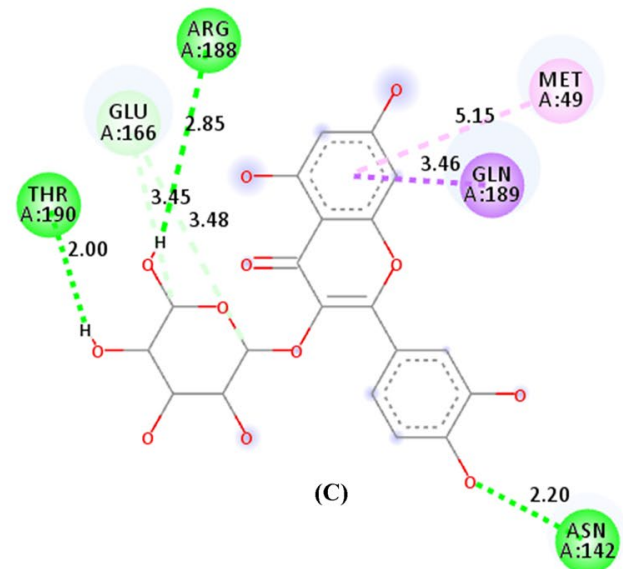

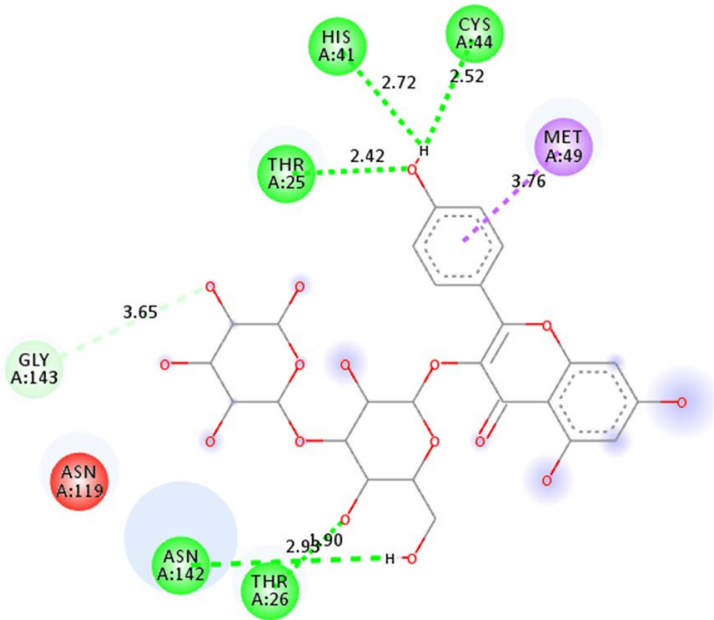

(D)

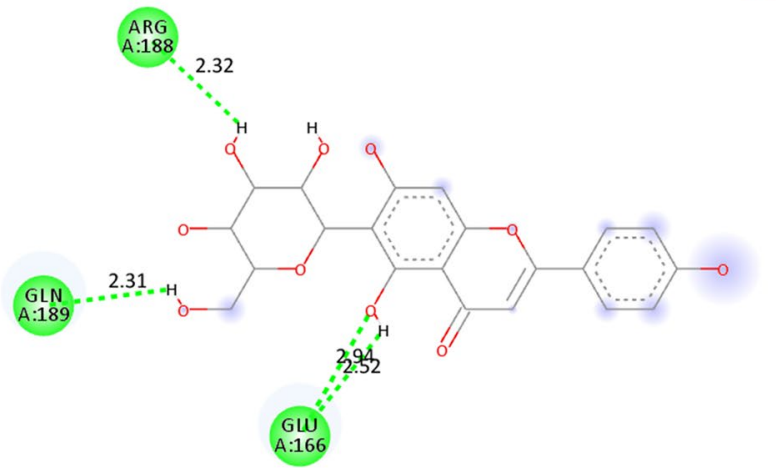

(E)

Fig. 4 Visualization of 2-dimensional ligand interactions between the amino acid residues of the active binding pockets of SARS-CoV-2 M ${ }^{\text {pro }}$ with (a) 3WL, (b) carmofur, (c) C_18, (d) C_4 and (e) C_5

(Carmofur) while the reference standards against furin had a drug score of 0.255768 (PGPRTRA) and 0.0831259 (Naphthofluorescein). Among the phytocompounds with the top 5 binding affinities towards SARS-CoV-2 $\mathrm{M}^{\text {pro }}$ and furin, C_18 (0.6301938), C_4 (0.4808296) and C_5 (0.4577336) had the highest drug scores (Tables 3 and 4). The drug score of all the three phytocompounds is higher than all the standard references except for the co-crystal inhibitor of SARS-CoV-2 M $\mathrm{M}^{\text {pro }}$ (3WL). As C_18, C_4 and C_5 were free from all possible signs of toxicity, they were subjected to further analysis to check whether they had interacted with the amino acid residues at the active binding site of the target proteins.

\section{Ligand interactions of three phytocompounds with the highest drug scores}

For SARS-CoV-2 $\mathrm{M}^{\text {pro }}$, the 2-dimensional interactions of the standard references (3WL and carmofur) and the phytocompounds (C_18, C_4, and C_5) with the amino acid residues at the active binding site is given in Fig. 4. The 3-dimensional biding pose of the phytocompounds and the standard references at the active binding pockets of SARS-CoV-2 $\mathrm{M}^{\text {pro }}$ is also given in Fig. 5. In general, the interacting amino acid residues of SARSCoV-2 $\mathrm{M}^{\text {pro }}$ are GLN189, GLN192, MET165, PRO168, THR190, GLU166, ARG188, MET49, ASN142, HIS41, THR25, CYS44, GLY143 and THR26 (Fig. 4). The binding parameters of the standard references and the phytocompounds with the amino acid residues at the active binding site of SARS-CoV-2 $\mathrm{M}^{\text {pro }}$ are given in Table 5 . The number of conventional hydrogen bonds formed by C_18 $(n=3)$, C_4 $(n=5)$, and C_5 $(n=4)$ with the amino acid residues at the active binding site of SARSCoV-2 $\mathrm{M}^{\text {pro }}$ is more than the number of hydrogen bonds formed by the standard references ' $3 \mathrm{WL}(n=2)$ and 'carmofur' $(n=2)$ (Fig. 4). Overall, C_18, C_4 , and C_5 showed different types of interactions with 6,7 , and 4 amino acid residues at the active binding site of SARS-CoV-2 $\mathrm{M}^{\text {pro }}$ respectively. Among the interacting amino acid residues of the active binding site of SARSCoV-2 $\mathrm{M}^{\text {pro }}$, GLN189 has the highest occurrence $(n=3)$ followed by ARG188 $(n=2)$, ASN142 $(n=2)$, MET49 $(n=2)$, GLU166 $(n=2)$, GLN192 $(n=2)$, THR190 $(n=1)$, THR25 $(n=1)$, HIS41 $(n=1)$, CYS44 $(n=1)$, 


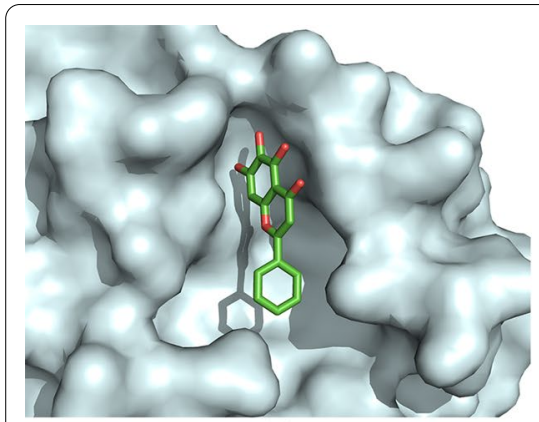

(A)

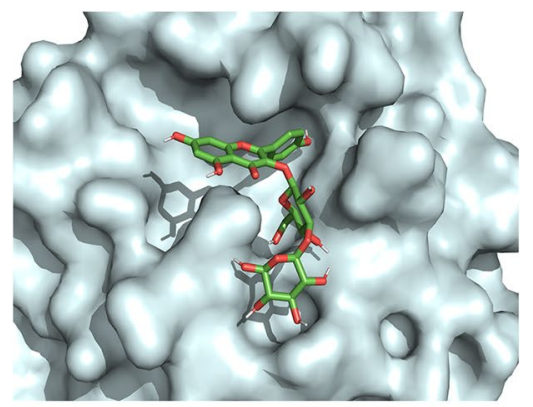

(D)

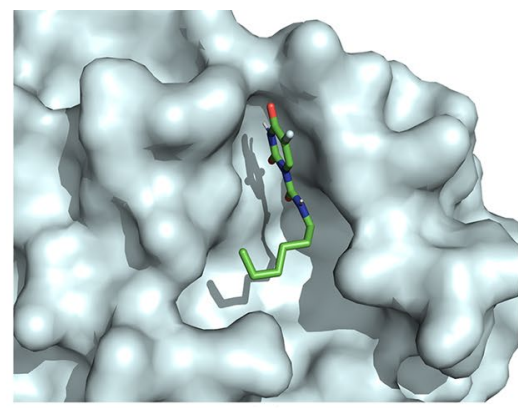

(B)

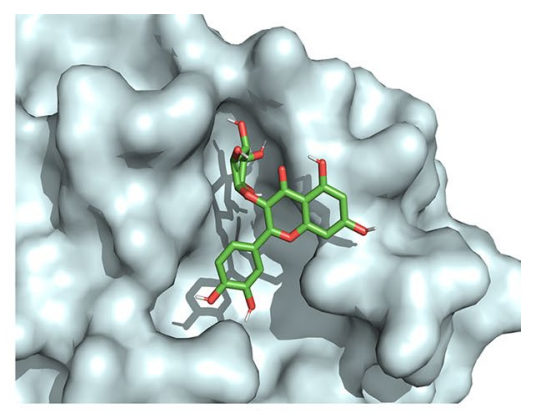

(C)

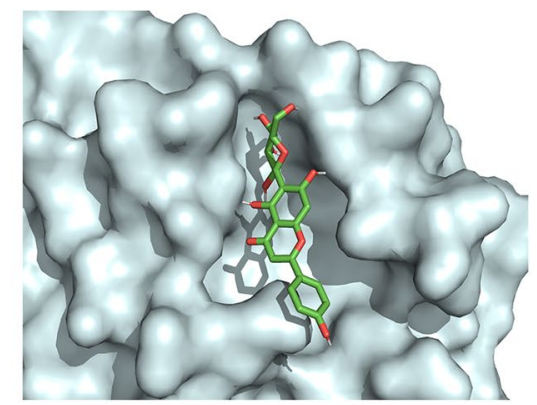

(E)

Fig. 5 3-dimensional view at the biding pose of (a) 3WL, (b) carmofur, (c) C_18, (d) C_4 and (e) C_5 at the active binding pockets of SARS-CoV-2 $\mathrm{M}^{\text {pro }}$

Table 5 Binding parameters of the phytocompounds and the standard references with the amino acid residues at the active binding site of SARS-COV-2 Mpro

\begin{tabular}{|c|c|c|c|c|c|}
\hline SI. No & Compound ID & Conventional hydrogen bonding & Hydrophobic interaction & $\begin{array}{l}\text { Carbon-hydrogen } \\
\text { interaction }\end{array}$ & $\begin{array}{l}\text { Electrostatic } \\
\text { interaction }\end{array}$ \\
\hline 1 & C_18 & THR190, ARG188, ASN142 & MET49, GLN189 & GLU166 & - \\
\hline 2 & C_4 & THR25, HIS41, CYS44, ASN142, THR26 & MET49 & GLY143 & - \\
\hline 3 & C_5 & ARG188, GLN189, GLU166 & - & - & - \\
\hline 4 & $3 W L$ & GLN189, GLN192 & - & - & MET165 \\
\hline 5 & Carmofur & GLN192 & PRO168 & - & - \\
\hline
\end{tabular}

THR26 $(n=1), \operatorname{GLY143}(n=1), \operatorname{MET} 165(n=1)$, and PRO168 $(n=1)$.

For furin, the 2-dimensional interactions of the standard references (PGPRTRA and naphthofluorescein) and the phytocompounds (C_18, C_4 , and C_5) with the amino acid residues at the active binding site is given in Fig. 6. The 3-dimensional biding pose of the phytocompounds and the standard references at the active binding pockets of furin is also given in Fig. 7 . In general, the interacting amino acid residues of furin are ASP258, GLU299, ASN295, FMT601, SER368, HIS194, GLY229, LEU227, ASP191, THR365, ARG193, ARG197, ARG298 and HIS364 (Fig. 6). The binding parameters of the standard references and the phytocompounds with the active binding site amino acid residues of furin are given in Table 6. The number of conventional hydrogen bonds formed by $C_{-} 18, C_{-} 4$, C_5, PGPRTRA, and naphthofluorescein are $8,3,5$, 7, and 2 respectively (Fig. 6). Overall, C_18, C_4, and C_5 showed different types of interactions with 6,5 , and 5 amino acid residues at the active binding site of furin respectively. Among the interacting amino acid residues of the active binding site of furin, FMT601 has the highest occurrence $(n=4)$ followed by ASN295 $(n=3)$, SER368 $(n=3)$, THR365 $(n=3)$, HIS194 $(n=2)$, LEU227 $(n=2)$, ARG298 $(n=2)$, ASP258 $(n=1)$, GLU299 $(n=1)$, GLY229 $(n=1)$, ASP191 $(n=1)$, ARG193 $(n=1)$, ARG197 $(n=1)$, and HIS364 $(n=1)$. 


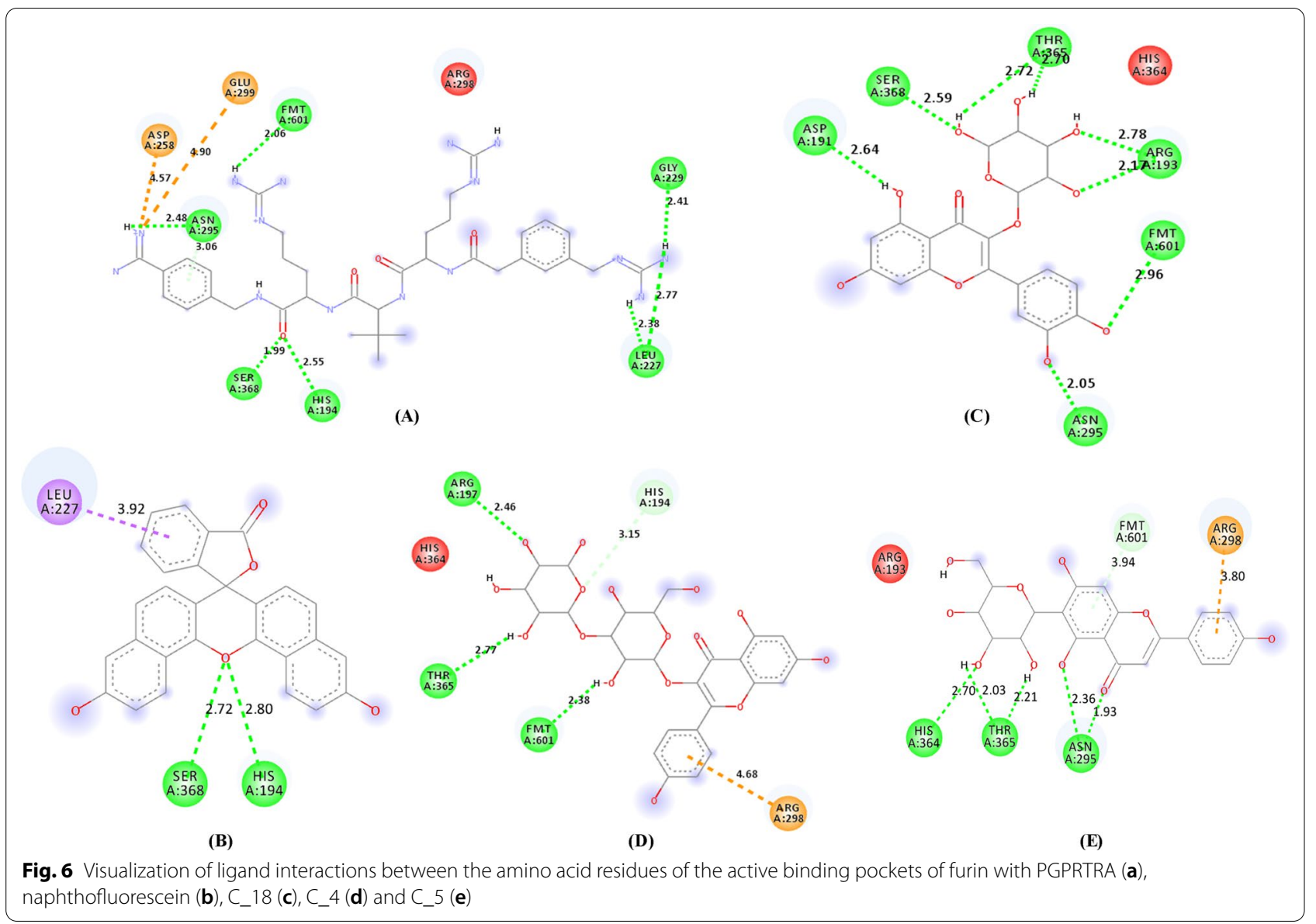

A hydrogen bond is an important facilitator for proper binding between a protein and a ligand [61]. In a similar fashion with the reference standards, the phytocompounds (C_18, C_4 , and C_5) showed a good number of conventional hydrogen bonding with the amino acid residues at the active binding site of the target proteins (SARS-CoV-2 $\mathrm{M}^{\text {pro }}$ and furin) (Figs. 4 and 6). Hydrophobic interactions are noncovalent bonding interactions that are considered to be crucial for protein folding and protein-ligand interactions [62, 63]. Two phytocompounds (C_18 and C_5) showed hydrophobic interactions with the amino acid residues at the active binding site of SARS-CoV-2 $\mathrm{M}^{\text {pro }}$ (Fig. 4). Electrostatic interactions are also reported to be important for protein stability, function, flexibility, and folding [63]. Two phytocompounds (C_4 and C_5) showed electrostatic interactions with the amino acid residues at the active binding site of furin (Fig. 6). Analysis of ligand interactions revealed that all the three phytocompounds (C_18, C_4 , and C_5) interacted with different amino acid residues at the active binding site of the target proteins (SARS-CoV-2 $\mathrm{M}^{\text {pro }}$ and furin).
Pharmacological relevance of three phytocompounds with the highest drug scores in COVID-19 pandemic

Quercetin-3-O- $\alpha$-L-rhamnopyranoside (C_18) has been reported to exhibit antiviral activity against the influenza A virus (H1N1) [64]. SARS-CoV-2 is a viral pathogen that primarily affects the respiratory system [65]. Pharmacological activities of C_18 like antioxidant, anti-obesity, and other activities have also been reported [66-68]. The antioxidant activity of C_18 might prove beneficial in SARS-CoV-2 infection as COVID-19 is associated with oxidative stress [65]. In addition to $A$. pennata, Quercetin-3-O- $\alpha$-L-rhamnopyranoside is also found in other plants [64, 66-71]. Kaempferol 3-O- $\alpha-\mathrm{L}-$ rhamnopyranosyl- $(1 \rightarrow 4)$ - $\beta$-D-glucopyranoside (C_4) and isovitexin (C_5) were reported to inhibit cyclooxygenase (COX)-1 and COX-2 enzyme in a COX-1/COX2- catalyzed prostaglandin biosynthesis assay [32]. COX enzymes are of clinical relevance as they are pro-inflammatory agents that are inhibited by anti-inflammatory drugs [72]. The anti-inflammatory activity of C_5 against lipopolysaccharide-induced neuroinflammation has also been reported [73]. COVID-19 is associated with inflammation [74] and some studies suggest the treatment of 


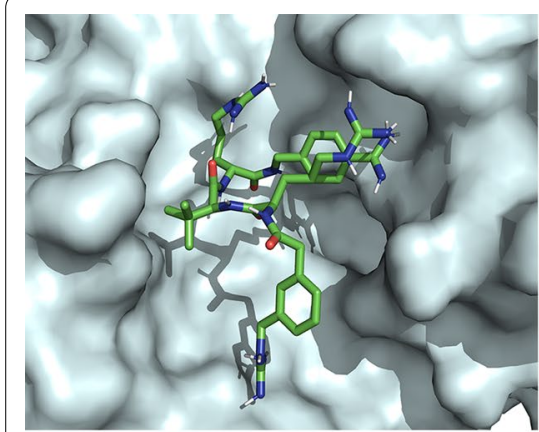

(A)

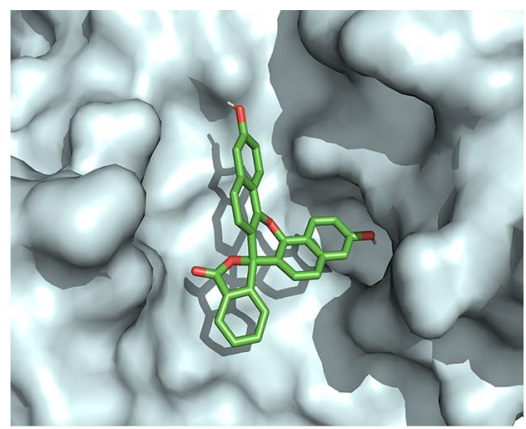

(B)

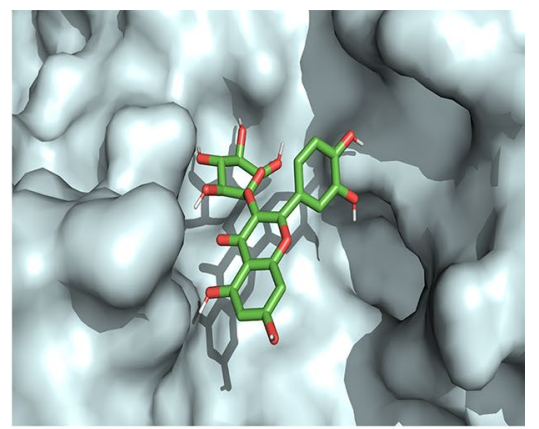

(C)

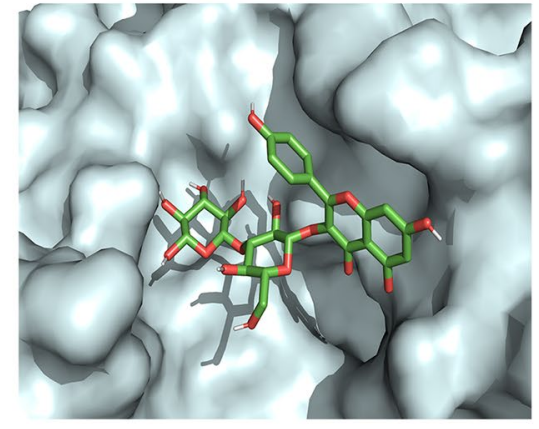

(D)

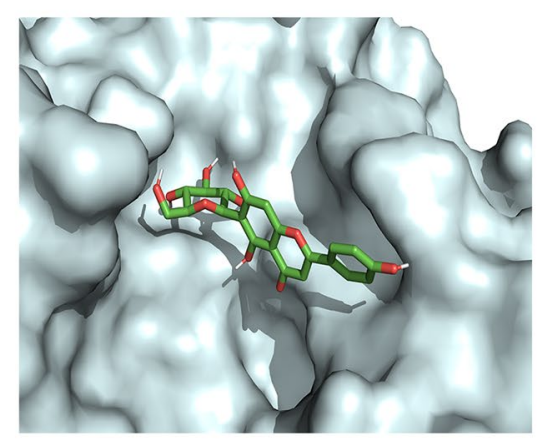

(E)

Fig. 7 3-dimensional view at the biding pose of (a) PGPRTRA, (b) Naphthofluorescein, (c) C_18, (d) C_4 and (e) C_5 at the active binding pockets of furin

Table 6 Binding parameters of the phytocompounds and the standard references with the amino acid residues at the active binding site of furin

\begin{tabular}{llllll}
\hline SI. No & Compound ID & Conventional hydrogen bonding & $\begin{array}{l}\text { Hydrophobic } \\
\text { interaction }\end{array}$ & $\begin{array}{l}\text { Carbon- } \\
\text { hydrogen } \\
\text { interaction }\end{array}$ & Electrostatic interaction \\
\hline 1 & C_18 & ASP191, SER368, THR365, ARG193, FMT601, ASN295 & - & - & - \\
2 & C_4 & ARG197, THR365, FMT601 & HIS194 & ARG298 \\
3 & C_5 & HIS364, THR365, ASN295 & - & FMT601 & ARG298 \\
4 & PGPRTRA & ASN295, FMT601, SER368, HIS194, LEU227, GLY229 & - & - & ASP258, GLU299 \\
5 & Naphthofluorescein & HIS194, SER368 & LEU227 & - & - \\
\hline
\end{tabular}

Table 7 Bioavailability score and synthetic accessibility of the phytocompounds

\begin{tabular}{llll}
\hline SI. No & Compound ID & $\begin{array}{l}\text { Bioavailability } \\
\text { score }\end{array}$ & $\begin{array}{l}\text { Synthetic } \\
\text { accessibility }\end{array}$ \\
\hline 1 & C_4 & 0.17 & 6.35 \\
2 & C_5 & 0.55 & 4.99 \\
3 & C_18 & 0.17 & 5.19 \\
\hline
\end{tabular}

COVID-19 by inhibition of COX-2 [75]. Moreover, the antioxidant activity of $\mathrm{C}_{-} 5$ has also been reported [76]. In addition to $A$. pennata, isovitexin (C_5) had also been isolated from other plants [77-81]. The existing data of the phytocompounds suggests that they could be considered as potential leads. However, the bioavailability and the degree of difficulty to synthesize a compound must be evaluated for the promising phytocompounds before they could be considered as potential leads.

\section{Bioavailability score of the three phytocompounds with the highest drug scores}

The process of drug development can be slowed down by bioavailability issues associated with a compound [52]. For a compound to be effective as a drug, it is important 


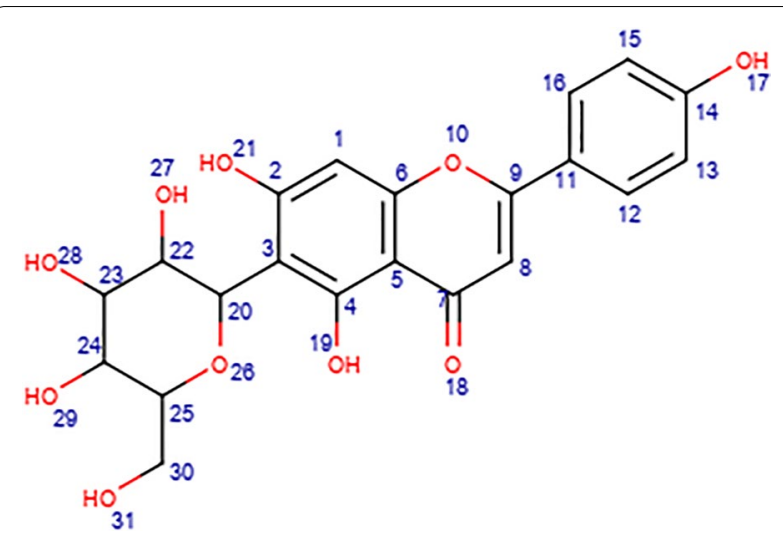

Fig. 8 Mapped structure of C_5

that a sufficient concentration of a compound is available within the systemic circulation for a specified period so that a compound can exert its pharmacological action on the body [51]. Just like toxicity, it is important to assess the bioavailability of a compound at an earlier stage in the drug development process to avoid unfruitful outcomes in the future. Therefore, the bioavailability of the phytocompounds (C_18, C_4 , and C_5) was determined with the SwissADME web tool. The SwissADME web tool determines the bioavailability based on the molecular properties and lipophilicity of a compound by applying different principles such as Lipinski's rule of 5, Ghose filter, Veber filter, Egan filter and Muegge filter [51]. Among the phytocompounds, C_5 has the highest bioavailability score (0.55) while C_4 and C_18 each have a low bioavailability score $(0.17)$ (Table 7$)$. The bioavailability study revealed that $C_{-} 5$ has better bioavailability than the other phytocompounds.

\section{Synthetic accessibility of the three phytocompounds with the highest drug scores}

During the process of virtual screening to identify promising lead compounds, it is preferable to filter out a non-toxic, biologically active compound having good bioavailability [51]. Along with this, the degree of difficulty to synthesize a compound is also a factor that needs to be taken into consideration while selecting the most promising compound [51]. In our study, we have assessed the degree of difficulty to synthesize a compound with the SwissADME web tool. Synthetic accessibility is a fingerprint-based computational approach that can be used to determine the level of difficulty for synthesizing a compound [51]. A compound with a synthetic accessibility score of 1 indicates that the compound can be easily synthesized while a synthetic accessibility score of 10 suggests that the compound will be very difficult to synthesize [51]. Among the phytocompounds, C_5 (4.99) has the best synthetic accessibility score followed by C_18 (5.19) and C_4 (6.35) (Table 7). The synthetic accessibility study revealed that C_ 5 will be easier to be synthesized in comparison to the other phytocompounds.

\section{Structure-activity relationship of the most promising phytocompound (C_5) and comparison with other studies} Based on the binding affinity towards the target proteins, molecular properties, drug-likeness, toxicity, ligand interactions, bioavailability and synthetic accessibility, C_5 (Isovitexin) has been found as the most promising phytocompound that could act as a potential lead. Although C_5 showed good ligand interactions with SARS-CoV-2 $\mathrm{M}^{\text {pro }}$ and furin, it is important to make sure that C_5 interacted specifically with the active amino acid residues at the active binding site of the target proteins. Therefore, we decided to compare our experimental findings with several studies published by other researchers.

From Figs. 4, 6, and 8, it can be observed that the same functional group located at different positions on C_5 interacted with different amino acid residues at the active binding site of SARS-CoV-2 $\mathrm{M}^{\text {pro }}$ and furin. The structure-activity relationship of $\mathrm{C}_{-} 5$ revealed that the $-\mathrm{OH}$ group at position 19 of the A-ring interacted with GLU166 of SARS-CoV-2 Mpro (Figs. 4 and 8) and also interacted with ASN295 of furin (Figs. 6 and 8). Several in-silico studies reported that many phytocompounds either formed conventional hydrogen bonds or interacted with GLU166 of SARS-CoV-2 Mpro [82-84]. An in-silico study also reported that several phytocompounds either formed conventional hydrogen bonds or interacted with ASN295 of furin [85]. The -OH group at position 28 of the 6-C glucoside attached to the A-ring of C_5 inter-

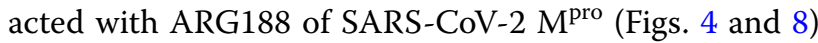
and also interacted with HIS364 and THR365 of furin (Figs. 6 and 8). Interestingly, other phytocompounds have also been reported to interact with ARG188 of SARSCoV-2 M $M^{\text {pro }}[82,86]$. Also, several phytocompounds were reported to either form conventional hydrogen bonds or interact with HIS364 and THR365 of furin [85].

The $-\mathrm{OH}$ group at position 31 of the $6-\mathrm{C}$ glucoside attached to the A-ring of C_5 interacted with GLN189 of SARS-CoV-2 $\mathrm{M}^{\text {pro }}$ (Figs. 4 and 8). Other compounds were also reported to either form conventional hydrogen bonds or interacted with GLN189 of SARS-CoV-2 Mpro [86, 87]. The oxygen atom at position 18 of the C-ring formed a conventional hydrogen bond with ASN295 of furin (Figs. 6 and 8). Several phytocompounds were also reported to either form a conventional hydrogen bond or interacted with ASN295 of furin [85]. The -OH group at position 27 of the $6-\mathrm{C}$ glucoside attached to the A-ring formed a conventional hydrogen bond with THR365 
(Figs. 6 and 8). Many phytocompounds either formed a conventional hydrogen bond or interacted with THR365 of furin [85]. The B-ring of the $\mathrm{C}_{6}-\mathrm{C}_{3}-\mathrm{C}_{6}$ scaffold of C_5 formed electrostatic interaction with ARG298 of furin (Figs. 6 and 8). Several phytocompounds were also reported to interact with ARG298 of furin [85]. It was observed that phytocompounds that interacted with the same active site residues of the target proteins similar to what we reported for isovitexin were published as potential inhibitors of SARS-CoV-2 $\mathrm{M}^{\text {pro }}$ and furin. After comparison with other studies, it was observed that C_5 has the potential to interact specifically with the active amino acid residues at the active binding site of SARS-CoV-2 $\mathrm{M}^{\text {pro }}$ and furin.

Isovitexin (C_5) is apigenin with a 6-C glucoside attached to position 3 (Fig. 8) of the A-ring [88]. Recently, a study showed that the methanol-trifluoroacetic acid leaf extract of Vitis vinifera was able to effectively inhibit the replication of SARS-CoV-2 in-vitro. From about 40 phenolic compounds present in the leaf extract of $V$. vinifera, isovitexin (C_5, apigenin-6-C glucoside) was among the most abundant phenolic compounds present in the leaf extract [89]. Although the study did not identify the phenolic compound responsible for the inhibition of SARS-CoV-2, the fact that isovitexin was among the major phytoconstituents present in the plant extract suggests that isovitexin might play an important role in the inhibition of SARS-CoV-2.

Interestingly, an in-silico study found apigenin as a potential inhibitor of SARS-CoV-2 $\mathrm{M}^{\text {pro }}$ [83]. A molecular docking simulation-based in-silico study found apigenino-7-glucuronide as a potential inhibitor of SARS-CoV-2 $\mathrm{M}^{\text {pro. }}$. Molecular dynamics simulation reveal stable conformation between the SARS-CoV-2 $\mathrm{M}^{\text {pro }}$ and apigenino-7-glucuronide complex [84]. The in-silico findings reported by other researchers suggest a stable proteinligand interaction between apigenin (with or without its sugar moiety) with SARS-CoV-2 $\mathrm{M}^{\text {pro }}$.

Pharmacophores could be any part of the structure of a compound that interacts with a target protein to exert a pharmacological activity [90]. The oxygen atom at position 18 of the $\mathrm{C}$-ring, the $-\mathrm{OH}$ group at position 19 of the A-ring, the $-\mathrm{OH}$ group at position 27,28 , and 31 of the 6 -C-glucoside attached to the A-ring, and the B-ring could be considered as the pharmacophores in the structure of isovitexin as they had interacted with the active amino acid residues at the active binding site of SARS-CoV-2 $\mathrm{M}^{\text {pro }}$ and furin (Figs. 4, 6, and 8). All these pharmacophores are attached to the basic flavonoid $\left(\mathrm{C}_{6}-\mathrm{C}_{3}-\mathrm{C}_{6}\right)$ scaffold. Therefore, we conclude that compounds having oxygen atom at position 18 attached to the $\mathrm{C}$-ring, $-\mathrm{OH}$ group at position 19 attached to the A-ring, and the presence of a 6-C-glucoside that is attached to the A-ring of a $\mathrm{C}_{6}-\mathrm{C}_{3}-\mathrm{C}_{6}$ scaffold (Fig. 8) could offer the best alternative to develop new leads against SARS-CoV-2.

\section{Conclusions}

Since SARS-CoV-2 utilizes its main viral protease ' $M$ pro' and human protease 'furin' to achieve cellular entry and viral replication, we have screened 29 phytocompounds reported to be isolated from $A$. pennata for potential leads using computational studies. Initially, our computational guided study revealed three flavonoids viz. quercetin3-O- $\alpha$-L-rhamnopyranoside, kaempferol 3-O- $\alpha$-Lrhamnopyranosyl- $(1 \rightarrow 4)-\beta$-D-glucopyranoside, and isovitexin as promising phytocompounds against SARS$\mathrm{CoV}-2$. However, quercetin-3-O- $\alpha$-L-rhamnopyranoside and kaempferol 3-O- $\alpha$-L-rhamnopyranosyl- $(1 \rightarrow 4)-\beta-\mathrm{D}$ glucopyranoside were not selected for further studies as they had bioavailability issues and were also found as difficult to synthesize. Based on binding affinity, molecular properties, drug-likeness, toxicity parameters, ligand interactions, bioavailability score, synthetic accessibility, structure-activity relationship and other supporting literary evidence, we found that isovitexin (apigenin-6-Cglucoside) was the most promising phytocompound to potentially inhibit the cellular entry and viral replication of SARS-CoV-2. Also, based on the structure-activity relationship, we conclude that compounds having oxygen atom at position 18 attached to the $\mathrm{C}$-ring, $-\mathrm{OH}$ group at position 19 attached to the A-ring, and the presence of a 6-C-glucoside that is attached to the A-ring of a $\mathrm{C}_{6}-\mathrm{C}_{3}-\mathrm{C}_{6}$ scaffold could offer the best alternative to develop new leads against SARS-CoV-2. As the evidence provided in our study is limited to in-silico data only, further investigations such as in-vitro studies are suggested to understand the complete inhibitory potential of the phytocompound against SARS-CoV-2.

\section{Abbreviations}

COVID-19: Coronavirus disease 2019; SARS-CoV-2: Severe acute respiratory syndrome coronavirus 2; ${ }^{\text {pro }}$ : Main protease; SP: Spike protein; PGPRTRA: Para-guanidinomethyl-Phac-R-Tle-R-Amba.

\section{Acknowledgements}

The authors are thankful to the Department of Pharmaceutical Sciences, Dibrugarh University for providing the necessary facilities to carry out the work.

\section{Authors' contributions}

$J H Z$ and $H L$ developed the idea of the work. JHZ, NG and AS came up with the study design. JHZ carried out the works. NG, AS and DC analyzed and interpreted the results. JHZ and $\mathrm{HL}$ drafted the manuscript. NG, AS and DC provided additional inputs. HL carried out critical reviewing of the manuscript. All five authors wrote, read and approve the manuscript.

Funding

Not applicable. 


\section{Availability of data and materials}

Data and materials used in the study will be made available with proper request to the corresponding author.

\section{Declarations}

\section{Ethics approval and consent to participate}

Not applicable.

\section{Consent for publication}

Not applicable.

\section{Competing interests}

Not applicable.

\section{Author details}

${ }^{1}$ Department of Pharmaceutical Sciences, Faculty of Science and Engineering, Dibrugarh University, Dibrugarh, Assam 786004, India. ${ }^{2}$ Department of Zoology, Pachhunga Univeristy College, Aizawl, Mizoram 796001, India.

Received: 2 March 2021 Accepted: 29 September 2021

Published online: 09 October 2021

\section{References}

1. Narkhede RR, Pise AV, Cheke RS, Shinde SD (2020) Recognition of natural products as potential inhibitors of COVID-19 main protease (Mpro): InSilico evidences. Nat Prod Bioprospect 10:297-306

2. World Health Organization (2021) WHO Coronavirus disease (COVID-19) Dashboard. https://covid19.who.int/. Accessed 2 Feb 2021.

3. Centers for Disease Control and Prevention (2020) CDC COVID-19 Symptoms of Coronavirus. https://www.cdc.gov/coronavirus/2019-ncov/sympt oms-testing/symptoms.html. Accessed 4 Feb 2021.

4. Shende P, Khanolkar B, Gaud RS (2020) Drug repurposing: new strategies for addressing COVID-19 outbreak. Exp Rev Anti Infect Ther 3:1-18

5. Stasi C, Fallani S, Voller F, Silvestri C (2020) Treatment for COVID-19: an overview. Eur J Pharmacol 889:173644.

6. Regulatory Affairs Professional Society (2021) COVID-19 vaccine tracker. https://www.raps.org/news-and-articles/news-articles/2020/3/covid-19vaccine-tracker. Accessed 2 Feb 2021.

7. Ingrid T (2021) COVID-19: Norway investigates 23 deaths in frail elderly patients after vaccination. BMJ 372: n149.

8. Antonio ADS, Wiedemann LSM, Veiga-Junior VF (2020) Natural products' role against COVID-19. RSC Adv 10:23379-23393

9. Islam MT, Sarkar C, El-Kersh DM, Jamaddar S, Uddin SJ, Shilpi JA, Mubarak MS (2020) Natural products and their derivative against coronavirus: a review of the non-clinical and pre-clinical data. Phytother Res 34:2471-2492

10. Kim DW, Seo KH, Curtis-Long MJ, Oh KY, Oh JW, Cho JK, Lee KH, Park KH (2014) Phenolic phytochemical displaying SARS-CoV papain-like protease inhibition from the seeds of Psoralea corylifolia. J Enzyme Inhib Med Chem 29:59-63

11. Tahir UI Qamar M, Maryam A, Muneer I, Xing F, Ashfaq UA, Khan FA, Anwar F, Geesi MH, Khalid RR, Rauf SA, Siddiqi AR (2019) Computational screening of medicinal plant phytochemicals to discover potent pan-serotype inhibitors against dengue virus. Sci Rep 9:1433

12. Cheng Y, Chao T, Li C, Chiu M, Kao H, Wang S, Pang Y, Lin C, Tsai Y, Lee W, Tao M, Ho T, Wu P, Jang L, Chen P, Chang S, Yeh S (2020) Furin inhibitors block SARS-CoV-2 spike protein cleavage to suppress virus production and cytopathic effects. Cell Rep 33:108254.

13. Braun $E$, Sauter D, Furin-mediated protein processing in infectious diseases and cancer. Clin Transl Immunol. 2019;8: e1073.

14. Huang Y, Yang C, Xu X, Xu W, Liu S (2020) Structural and functional properties of SARS-CoV-2 spike protein: potential antivirus drug development for COVID-19. Acta Pharmacol Sin 41:1141-1149

15. Jin Z, Du X, Xu Y, Deng Y, Liu M, Zhao Y, Zhang B, Li X, Zhang L, Peng C, Duan $Y$, Yu J, Wang L, Yang K, Liu F, Jiang R, Yang X, You T, Liu X, Yang X, Bai F, Liu H, Liu X, Guddat LW, Xu W, Xiao G, Qin C, Shi Z, Jiang H, Rao Z, Yang
H (2020) Structure of $M^{\text {pro }}$ from SARS-CoV-2 and discovery of its inhibitors. Nature 582:289-293

16. Gildenhuys S (2020) Expanding our understanding of the role polyprotein conformation plays in the coronavirus life cycle. Biochem J 477:1479-1482

17. Prajapat M, Sarma P, Shekhar N, Avti P, Sinha S, Kaur H, Kumar S, Bhattacharyya A, Kumar H, Bansal S, Medhi B (2020) Drug targets for corona virus: a systematic review. Indian J Pharmacol 52:56-65

18. Robson B (2020) Computers and viral diseases. Preliminary bioinformatics studies on the design of a synthetic vaccine and a preventative peptidomimetic antagonist against the SARS-CoV-2 (2019-nCoV, COVID-19) coronavirus. Comput Biol Med 119:103670.

19. Wang Z, Yang L (2020) Turning the tide: Natural products and naturalproduct-inspired chemicals as potential counters to SARS-CoV-2 infection. Front Pharmacol 11:1013

20. Joshi T, Joshi T, Sharma P, Mathpal S, Pundir H, Bhatt V, Chandra S (2020) In silico screening of natural compounds against COVID-19 by targeting Mpro and ACE2 using molecular docking. Eur Rev Med Pharmacol Sci 24:4529-4536

21. Khanal P, Patil BM, Chand J, Naaz Y (2020) Anthraquinone derivatives as an immune booster and their therapeutic option against COVID-19. Nat Prod Bioprospect 10:325-335

22. Jo S, Kim S, Shin DH, Kim MS (2020) Inhibition of SARS-CoV 3CL protease by flavonoids. J Enzyme Inhib Med Chem 35:145-151

23. Meneguzzo F, Ciriminna R, Zabini F, Pagliaro M (2020) Review of evidence available on hesperidin-rich products as potential tools against COVID-19 and hydrodynamic cavitation-based extraction as a method of increasing their production. Processes 8:549

24. Russo M, Moccia S, Spagnuolo C, Tedesco I, Russo GL (2020) Roles of flavonoids against coronavirus infection. Chem Biol Interact 328:109211.

25. Aye MM, Aung HT, Sein MM, Armijos C (2019) A Review on the phytochemistry, medicinal properties and pharmacological activities of 15 selected Myanmar medicinal plants. Molecules 24:293

26. Kim A, Choi J, Htwe KM, Chin Y, Kim J, Yoon KD (2015) Flavonoid glycosides from the aerial parts of Acacia pennata in Myanmar. Phytochemistry 118:17-22

27. Rifai Y, Arai MA, Koyano T, Kowithayakorn T, Ishibashi M (2010) Terpenoids and a flavonoid glycoside from Acacia pennata leaves as hedgehog/GLImediated transcriptional inhibitors. J Nat Prod 73:995-997

28. Sowndhararajan K, Joseph JM, Manian S (2013) Antioxidant and free radical scavenging activities of Indian Acacias: Acacia leucophloea (Roxb.) Willd., Acacia ferruginea Dc., Acacia dealbata Link. and Acacia pennata (L.) Willd. Int J Food Prop 16:1717-1729

29. Bhuyan B, Baishya K (2013) Ethnomedicinal value of various plants used in the preparation of traditional rice beer by different tribes of Assam, India. Drug Invent Today 5:335-341

30. Nguyen V, Nguyen HT, Do L, Tuan W, Thuong PT, Phan T (2018) A new saponin with anti-HIV-1 protease activity from Acacia pennata. Nat Prod Commun 13:411-414

31. Lipipun V, Kurokawa M, Suttisri R, Taweechotipatr P, Pramyothin P, Hattori M, Shiraki K (2003) Efficacy of Thai medicinal plant extracts against herpes simplex virus type 1 infection in vitro and in vivo. Antiviral Res 60:175-180

32. Dongmo AB, Myyamoto T, Yoshikawa K, Arihara S, Lacaille-Dubois MA (2007) Flavonoids from Acacia pennata and their cyclooxygenase (COX-1 and (OX-2) inhibitory activities. Planta Med 73:1202-1207

33. Lalchhandama K (2013) Efficacy and structural effects of Acacia pennata root bark upon the avian parasitic helminth, Raillietina echinobothrida. Pharm J 5:17-21

34. Nanasombat S, Teckchuen N (2009) Antimicrobial, antioxidant and anticancer activities of Thai local vegetables. J Med Plant Res 3:443-449

35. Wongsa P, Chaiwarit J, Zamaludien A (2012) In vitro screening of phenolic compounds, potential inhibition against a-amylase and a-glucosidase of culinary herbs in Thailand. Food Chem 131:964-971

36. Judprasong K, Charoenkiatkul S, Sungpuag P, Vasanachitt K, Nakjamanong Y (2006) Total and soluble oxalate contents in Thai vegetables, cereal grains and legume seeds and their changes after cooking. J Food Compost Anal 19:340-347

37. Thongwat D, Ganranoo L, Chokchaisiri R (2017) Larvicidal and pupicidal activities of crude and fractionated extracts of Acacia pennata (L.) Willd. Subsp Insuavis shoot tips against Aedes aegypti (L.) (Diptera: Culicidae). Southeast Asian J Trop Med Public Health 48:27-36 
38. Changkija S (1999) Folk medicinal plants of the Nagas in India. Asian Folkl Stud 58:205-230

39. ChemAxon (2021) MarvinSketch 20.10. https://chemaxon.com/products/ marvin. Accessed 25 Jan 2021

40. RCSB Protein Data Bank (2021) 6M2N SARS-CoV-2 3CL protease (3CL pro) in complex with a novel inhibitor. https://www.rcsb.org/structure/6M2N. Accessed 25 Jan 2021.

41. RCSB Protein Data Bank (2021) 3WL 5,6,7-trihydorxy-2-phenyl4H-chromen-4-one. https://www.rcsb.org/ligand/3WL. Accessed 25 Jan 2021.

42. RCSB Protein Data Bank (2021) 4RYD X-ray structure of human furin in complex with the competitive inhibitor para-guanidinomethyl-Phac-RTle-R-Amba. https://www.rcsb.org/structure/4RYD. Accessed 25 Jan 2021.

43. RCSB Protein Data Bank (2021) PRD_001257 para-guanidinomethyl-phenylacetyl-Arg-(3-methylvaline)-Arg- (amidomethyl)benzamidine. https:// www.rcsb.org/ligand/PRD_001257. Accessed 25 Jan 2021.

44. Jin Z, Zhao Y, Sun Y, Zhang B, Wang H, Wu Y, Zhu Y, Zhu C, Hu T, Du X, Duan Y, Yu J, Yang X, Yang X, Yang K, Liu X, Guddat LW, Xiao G, Zhang L, Yang H, Rao Z (2020) Structural basis for the inhibition of SARS-CoV-2 main protease by antineoplastic drug carmofur. Nat Struct Mol Biol 27:529-532

45. PyRx website (2021) Python Prescription Virtual Screening Tool. https:// pyrx.sourceforge.io/. Accessed 24 Jan 2021.

46. Trott O, Olson AJ (2010) AutoDock Vina: improving the speed and accuracy of docking with a new scoring function, efficient optimization, and multithreading. J Comput Chem 31:455-461

47. Dallakyan S, Olson AJ (2015) Small-molecule library screening by docking with PyRx. Methods Mol Biol 1263:243-250

48. Hassan NM, Alhossary AA, Mu Y, Kwoh C (2017) Protein-ligand blind docking using QuickVina-W with inter-process spatio-temporal integration. Sci Rep 7:15451

49. Sander T, Freyss J, Von Korff M, Rufener C (2015) DataWarrior: an opensource program for chemistry aware data visualization and analysis. J Chem Inf Model 55:460-473

50. PyMOL (2021) The PyMOL Molecular Graphics System, Version 2.4.1 Schrodinger, LLC. https://www.schrodinger.com/products/pymol. Accessed 23 Jan 2021.

51. Daina A, Michielin O, Zoete V (2017) SwissADME: a free web tool to evaluate pharmacokinetics, drug-likeness and medicinal chemistry friendliness of small molecules. Sci Rep 7:42717

52. Pathak K, Raghuvanshi S (2015) Oral bioavailability: issues and solutions via nanoformulations. Clin Pharmacokinet 54:325-357

53. Lomarat P, Chancharunee S, Anantachoke N, Kitphati W, Sripha K, Bunyapraphatsara N (2015) Bioactivity-guided separation of the active compounds in Acacia pennata responsible for the prevention of Alzheimer's disease. Nat Prod Commun 10:1431-1434

54. EL-Taher EMM, El-Sherei MM, El Dine RS, El Naggar DMY, Khalil WKB, Kassem SM, El Khateeb A, Kassem MES (2021) Acacia pennata L. leaves: chemical profiling and impact on DNA damage, alteration of genotoxic ity - related genes expression and ROS generation in hepatic tissues of acetaminophen treated male rats. Adv Tradit Med. https://doi.org/10. 1007/s13596-020-00527-6.

55. Anand Ganapathy A, Hari Priya VM, Kumaran A (2021) Medicinal plants as a potential source of Phosphodiesterase-5 inhibitors: a review. J Ethnopharmacol 267.

56. Wong G, He S, Siragam V, Bi Y, Mbikay M, Chretien M, Qiu X (2017) Antiviral activity of quercetin-3- $\beta$-O-D-glucoside against Zika virus infection. Virol Sin 32:545-547

57. Lani R, Hassandarvish P, Shu MH, Phoon WH, Chu JJ, Higgs S, Vanlandingham D, Abu Bakar S, Zandi K (2016) Antiviral activity of selected flavonoids against Chikungunya virus. Antiviral Res 133:50-61

58. Jo S, Kim S, Kim DY, Kim MS, Shin DH (2020) Flavonoids with inhibitory activity against SARS-CoV-2 3CLpro. J Enzyme Inhib Med Chem 35:1539-1544

59. Guengerich FP (2011) Mechanisms of drug toxicity and relevance to pharmaceutical development. Drug Metab Pharmacokinet 26:3-14

60. Openmolecules.org (2020) Overall Drug Score. http://www.openmolecu les.org/propertyexplorer/drug-score.html\#: :text=The\%20drug\%20sco re\%20combines\%20druglikeness, ds\%20is\%20the\%20drug\%20score. Accessed 5 Feb 2021.
61. Chen D, Oezguen N, Urvil P, Ferguson C, Dann SM, Savidge TC (2016) Regulation of protein-ligand binding affinity by hydrogen bond pairing. Sci Adv 2: e1501240.

62. de Freitas RF, Schapira M (2017) A systematic analysis of atomic proteinligand interactions in the PDB. Medchemcomm 8:1970-1981

63. Kumar S, Nussinov R (2002) Close-range electrostatic interactions in proteins. ChemBioChem 3:604-617

64. Mehrbod P, Ebrahimi SN, Fotouhi F, Eskandari F, Eloff JN, McGaw LJ, Fasina FO (2019) Experimental validation and computational modeling of anti-influenza effects of quercetin-3-O-a-L-rhamnopyranoside from indigenous south African medicinal plant Rapanea melanophloeos. BMC Complement Altern Med 19:346

65. Chernyak BV, Popova EN, Prikhodko AS, Grebenchikov OA, Zinovkina LA, Zinovkin RA (2020) COVID-19 and oxidative stress. Biochemistry (Mosc) 85:1543-1553

66. Kim SH, Kim JK, Lee YS, Bae YS, Lim SS (2010) Inhibitory effect of quercetin-3-O-aa-L-rhamnopyranoside from Chamaecyparis obtuse on aldose reductase and sorbitol accumulation. Korean J Medicinal Crop Sci 18:305-310

67. Park JY, Kim CS, Park KM, Chang PS (2019) Inhibitory characteristics of flavonol-3-O-glycosides from Polygonum aviculare L. (common knotgrass) against porcine pancreatic lipase. Sci Rep 9:18080.

68. Han H, Xu B, Amin A, Li H, Yu X, Gong M, Zhang L (2019) Quercetin-3O-a-L-rhamnopyranoside derived from the leaves of Lindera aggregata (Sims) Kosterm. evokes the autophagy-induced nuclear factor erythroid 2-related factor 2 antioxidant pathway in human umbilical vein endothelial cells. Int J Mol Med 43:461-474

69. Tostes JBF, Silva AJR, Kuster RM (2019) Isolation and characterization of polyphenols from Euphorbia heterophylla L. (Euphorbiaceae) leaves. Rev Fitos 13:49-60

70. Materska M, Perucka I, Stochmal A, Piacente S, Oleszek W (2003) Quantitative and qualitative determination of flavonoids and phenolic acid derivatives from pericarp of hot pepper fruit cv. Bronowicka Ostra. Polish J Food Nutr Sci 53:72-76

71. Okonkwo CJ, Njoku OU, Okonkwo TJN, Afieroho OE, Proksch P (2016) Two new acylated flavonol glycosides from Mimosa pigra L. leaves sub-family Mimosoideae. Future J Pharm Sci 2:71-75

72. Fitzpatrick FA (2004) Cyclooxygenase enzymes: regulation and function. Curr Pharm Des 10:577-588

73. Liu B, Huang B, Hu G, He D, Li Y, Ran X, Du J, Fu S, Liu D (2019) Isovitexinmediated regulation of microglial polarization in lipopolysaccharideinduced neuroinflammation via activation of the CaMKKB/AMPK-PGC-1a signaling axis. Front Immunol 10:2650

74. Tay MZ, Poh CM, Renia L, MacAry PA, Ng LFP (2020) The trinity of COVID-19: immunity, inflammation and intervention. Nat Rev Immunol 20:363-374

75. Baghaki S, Yalcin CE, Baghaki HS, Aydin SY, Daghan B, Yavuz E (2020) COX2 inhibition in the treatment of COVID-19: Review of literature to propose repositioning of celecoxib for randomized controlled studies. Int J Infect Dis 101:29-32

76. Lv H, Yu Z, Zheng Y, Wang L, Qin X, Cheng G, Ci X (2016) Isovitexin exerts anti-inflammatory and anti-oxidant activities on lipopolysaccharideinduced acute lung injury by inhibiting MAPK and NF-KB and activating HO-1/Nrf2 pathways. Int J Biol Sci 12:72-86

77. Guimarães CC, Oliveira DD, Valdevite M, Saltoratto AL, Pereira SI, França Sde C, Pereira AM, Pereira PS (2015) The glycosylated flavonoids vitexin, isovitexin, and quercetrin isolated from Serjania erecta Radlk (Sapindaceae) leaves protect $P C 12$ cells against amyloid- $\beta 25-35$ peptideinduced toxicity. Food Chem Toxicol 86:88-94

78. Fu Y, Zu Y, Liu W, Hou C, Chen L, Li S, Shi X, Tong M (2007) Preparative separation of vitexin and isovitexin from pigeonpea extracts with macroporous resins. J Chromatogr A 1139:206-213

79. Pang S, Ge Y, Wang LS, Liu X, Lin CW, Yang H (2013) Isolation and purification of orientin and isovitexin from Thlaspi arvense Linn. Adv Mat Res 781-784:615-618

80. Sientzoff P, Hubert J, Janin C, Voutquenne-Nazabadioko L, Renault JH, Nuzillard JM, Harakat D, Magid AA (2015) Fast identification of radical scavengers from Securigera varia by combining ${ }^{13} \mathrm{C}-\mathrm{NMR}$-Based dereplication to bioactivity-guided fractionation. Molecules 20:14970-14984

81. Yuan Z, Lv H, Wang X, Li G, Suo Y, Zhang Z, Wang H (2016) Separation and purification of four tannins from Potentilla parvifolia Fisch. (Rosaceae) 
using high-speed counter-current chromatography. Sep Sci Technol 51:2020-2027

82. Cherrak SA, Merzouk H, Mokhtari-Soulimane N (2020) Potential bioactive glycosylated flavonoids as SARS-CoV-2 main protease inhibitors: A molecular docking and simulation studies. PLOS ONE 15(10): e0240653.

83. Abdul-Hammed M, Adedotun IO, Olajide M, Irabor CO, Afolabi TI, Gbadebo IO, Rhyman L, Ramasami P (2021) Virtual screening, ADMET profiling, PASS prediction, and bioactivity studies of potential inhibitory roles of alkaloids, phytosterols, and flavonoids against COVID-19 main protease (M ${ }^{\text {pro }}$. Nat Prod Res 9:1-7

84. Gowrishankar S, Muthumanickam S, Kamaladevi A, Karthika C, Jothi R, Boomi P, Maniazhagu D, Pandian SK. Promising phytochemicals of traditional Indian herbal steam inhalation therapy to combat COVID-19-an in silico study. Food Chem Toxicol. 2021; 148:111966.

85. Vardhan S, Sahoo SK (2021) Virtual screening by targeting proteolytic sites of furin and TMPRSS2 to propose potential compounds obstructing the entry of SARS-CoV-2 virus into human host cells. J Tradit Complement Med. doi 10.1016\%2Fj.jtcme.2021.04.001.

86. Gurung AB, Ali MA, Lee J, Farah MA, Al-Anazi KM (2020) Unravelling lead antiviral phytochemicals for the inhibition of SARS-CoV-2 Mpro enzyme through in silico approach. Life Sci 255:117831.
87. Gurung AB, Ali MA, Lee J, Abul Farah M, Al-Anazi KM (2020) In silico screening of FDA approved drugs reveals ergotamine and dihydroergotamine as potential coronavirus main protease enzyme inhibitors. Saudi J Biol Sci 27(10):2674-2682

88. He M, Min JW, Kong WL, He XH, Li JX, Peng BW (2016) A review on the pharmacological effects of vitexin and isovitexin. Fitoterapia 115:74-85

89. Zannella C, Giugliano R, Chianese A, Buonocore C, Vitale GA, Sanna G, Sarno F, Manzin A, Nebbioso A, Termolino P, Altucci L, Galdiero M, de Pascale D, Franci G (2021) Antiviral Activity of Vitis vinifera Leaf Extract against SARS-CoV-2 and HSV-1. Viruses 13(7):1263

90. Seidel T, Schuetz DA, Garon A, Langer T (2019) The pharmacophore concept and its applications in computer-aided drug design. Prog Chem Org Nat Prod 110:99-141

\section{Publisher's Note}

Springer Nature remains neutral with regard to jurisdictional claims in published maps and institutional affiliations.

\section{Submit your manuscript to a SpringerOpen ${ }^{\circ}$ journal and benefit from:}

- Convenient online submission

- Rigorous peer review

- Open access: articles freely available online

- High visibility within the field

- Retaining the copyright to your article

Submit your next manuscript at $\boldsymbol{\nabla}$ springeropen.com 